Atmos. Chem. Phys., 20, 13877-13903, 2020

https://doi.org/10.5194/acp-20-13877-2020

(C) Author(s) 2020. This work is distributed under

the Creative Commons Attribution 4.0 License.

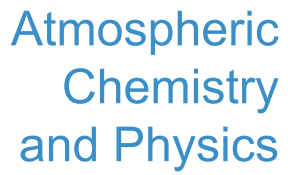

(c) (i)

\title{
Tropospheric aerosol hygroscopicity in China
}

\author{
Chao Peng ${ }^{1}$, Yu Wang ${ }^{2}$, Zhijun Wu' ${ }^{2}$, Lanxiadi Chen ${ }^{1,6}$, Ru-Jin Huang ${ }^{3}$, Weigang Wang ${ }^{4}$, Zhe Wang ${ }^{5}$, Weiwei Hu ${ }^{1}$, \\ Guohua Zhang ${ }^{1}$, Maofa $\mathrm{Ge}^{4,6,7}$, Min $\mathrm{Hu}^{2}$, Xinming Wang ${ }^{1,6,7}$, and Mingjin Tang ${ }^{1,6,7}$ \\ ${ }^{1}$ State Key Laboratory of Organic Geochemistry, Guangdong Key Laboratory of Environmental Protection and Resources \\ Utilization, and Guangdong-Hong Kong-Macao Joint Laboratory for Environmental Pollution and Control, Guangzhou \\ Institute of Geochemistry, Chinese Academy of Sciences, Guangzhou 510640, China \\ ${ }^{2}$ State Key Joint Laboratory of Environmental Simulation and Pollution Control, College of Environmental Sciences and \\ Engineering, Peking University, Beijing 100871, China \\ ${ }^{3}$ State Key Laboratory of Loess and Quaternary Geology, Center for Excellence in Quaternary Science and Global Change, \\ and Key Laboratory of Aerosol Chemistry and Physics, Institute of Earth Environment, Chinese Academy of Sciences, \\ Xi'an 710061, China \\ ${ }^{4}$ State Key Laboratory for Structural Chemistry of Unstable and Stable Species, Beijing National Laboratory for Molecular \\ Sciences (BNLMS), and CAS Research/Education Center for Excellence in Molecular Sciences, Institute of Chemistry, \\ Chinese Academy of Sciences, Beijing 100190, China \\ ${ }^{5}$ Division of Environment and Sustainability, The Hong Kong University of Science and Technology, Hong Kong, China \\ ${ }^{6}$ University of Chinese Academy of Sciences, Beijing 100049, China \\ ${ }^{7}$ Center for Excellence in Regional Atmospheric Environment, Institute of Urban Environment, Chinese Academy of \\ Sciences, Xiamen 361021, China
}

Correspondence: Mingjin Tang (mingjintang@gig.ac.cn)

Received: 22 April 2020 - Discussion started: 10 June 2020

Revised: 5 October 2020 - Accepted: 7 October 2020 - Published: 18 November 2020

\begin{abstract}
Hygroscopicity largely determines phase state, chemical reactivity, optical properties, and cloud nucleation activities of aerosol particles, thus significantly affecting their impacts on visibility, atmospheric chemistry, and climate. In the last 20 years, a large number of field studies have investigated the hygroscopicity of tropospheric aerosols in China under subsaturated and supersaturated conditions. Aerosol hygroscopicity measurements in China are reviewed in this paper: (1) a comprehensive summary and critical discussion of aerosol hygroscopicity measurements in China are provided; (2) available measurement data are compiled and presented under a consistent framework to enhance their accessibility and usability; and (3) current knowledge gaps are identified, and an outlook which could serve as guidelines for planning future research is also proposed.
\end{abstract}

\section{Introduction}

In the last few decades, rapid industrial, economic, and social developments in China have caused large emissions of gaseous and particulate pollutants in the troposphere (M. Li et al., 2017) where they are mixed with gases and aerosols from natural sources. Under unfavorable meteorological conditions (i.e., when air is stagnant and stable), severe air pollution occurs due to the accumulation of primary pollutants and, more importantly, the formation of secondary pollutants (Zhu et al., 2011; He et al., 2014; Zhang et al., 2015; An et al., 2019; Lu et al., 2019; X. Zhang et al., 2019). During severe air pollution events, $\mathrm{PM}_{2.5}$ could exceed a few hundred micrograms per cubic meter $\left(\mu \mathrm{g} \mathrm{m}^{-3}\right)$ (Guo et al., 2014; Huang et al., 2014), and $\mathrm{O}_{3}$ could reach up to $>200 \mathrm{ppbv}$ (T. Wang et al., 2017). The concept of air pollution complex has been proposed to describe the complexity of air pollution in China, which is characterized by complex sources and complex interactions of a myriad of gaseous and particulate pollutants (Zhu et al., 2011; Lu et al., 2019; Chu et 
al., 2020). Thanks to the implementation of effective air pollution control measures, a substantial decrease in $\mathrm{PM}_{2.5}$ has occurred nationwide in the last several years $(\mathrm{Q}$. Zhang et al., 2019); however, a slight but significant increase in $\mathrm{O}_{3}$ has been observed in many regions during the same period (K. Li et al., 2019; Lu et al., 2020), revealing the complexity and difficulty in synergistic control of $\mathrm{PM}_{2.5}$ and $\mathrm{O}_{3}$.

Hygroscopicity, one of the most important physicochemical properties of aerosols, determines the amount of water associated with aerosol particles under ambient conditions (mainly relative humidity and, to a lesser extent, temperature) and significantly affects their environmental and climatic impacts (Kreidenweis and Asa-Awuku, 2014; Tang et al., 2019). Hygroscopicity is referred to as hygroscopic properties under subsaturated conditions from a specific view, while from a general view, it is referred to as both hygroscopic properties under subsaturated conditions and cloud condensation nucleation (CCN) activities under supersaturated conditions. Due to their hygroscopicity, aerosol particles will take up water (i.e., hygroscopic growth) and lead to an increase in particle mass and size (Kreidenweis and AsaAwuku, 2014; Tang et al., 2016; Z. Wu et al., 2018; Tang et al., 2019). Therefore, hygroscopicity largely determines optical properties of aerosols and as a result their impacts on visibility and direct radiative forcing under subsaturated conditions (Titos et al., 2016; Zhao et al., 2019); on the other hand, hygroscopicity is also closely linked to $\mathrm{CCN}$ activities of aerosols and thus their abilities to form cloud droplets under supersaturated conditions (Kreidenweis and Asa-Awuku, 2014; Farmer et al., 2015; Tang et al., 2016), thereby having important implications for their indirect radiative forcing (Dusek et al., 2006; McFiggans et al., 2006; Farmer et al., 2015). Furthermore, hygroscopicity determines aerosol liquid water content (ALWC) and thus phase state, acidity, and chemical reactivities of aerosols (Bertram and Thornton, 2009; Liu et al., 2017; Tang et al., 2017; Z. Wu et al., 2018), playing critical roles in secondary aerosol formation and the removal and production of trace gases. In addition, hygroscopic growth measurements can provide valuable insights into mixing states of aerosols (Swietlicki et al., 2008; Riemer et al., 2019). Due to its importance, tropospheric aerosol hygroscopicity has been investigated in China by a number of field studies in the last 10-20 years, as reviewed in this paper.

Swietlicki et al. (2008) summarized and analyzed hygroscopic properties of ambient aerosols measured using $\mathrm{H}$ TDMA (hygroscopic tandem differential mobility analyzer) prior to September 2007, when ambient aerosol hygroscopicity was seldom explored in China. The effects of hygroscopicity on aerosol light scattering have been reviewed and summarized on a global scale (Titos et al., 2016; Burgos et al., 2019), and a very recent paper also briefly summarizes aerosol light scattering enhancement studies in China (Zhao et al., 2019). A book chapter (Kreidenweis and Asa-Awuku, 2014) discussed in brief hygroscopic growth and light scattering enhancement of ambient aerosols, but only a few mea- surements conducted in China were included. In addition, a recent paper (Tang et al., 2019) has reviewed aerosol hygroscopicity measurement techniques, but it only discussed several exemplary studies to illustrate how specific techniques can help us better understand tropospheric aerosol hygroscopicity.

In the last few decades, a number of field studies have investigated tropospheric aerosol hygroscopicity in China. However, a general overview of spatial and temporal variations of aerosol hygroscopicity in China is yet to be provided, and the dependence of aerosol hygroscopicity on aerosol composition, mixing state, etc. has not been fully elucidated. In this paper, we provide a comprehensive review of the hygroscopic properties of ambient aerosols measured using $\mathrm{H}-$ TDMA in China; in addition, CCN activities of tropospheric aerosols measured in China are also reviewed and discussed. Through the use of the single hygroscopicity parameter $(\kappa)$, we attempt to reconcile hygroscopic properties examined at $<100 \%$ relative humidity (RH) with CCN activities measured at $>100 \% \mathrm{RH}$. A number of studies measured light scattering enhancement factors, $f(\mathrm{RH})$, of ambient aerosols in China (Zhao et al., 2019), but most of these studies are not included herein for two reasons: (1) $f(\mathrm{RH})$ measurements in China have been reviewed in brief very recently (Zhao et al., 2019), and (2) it is not trivial to convert measured $f(\mathrm{RH})$ to growth factors or $\kappa$ values (Kreidenweis and Asa-Awuku, 2014). Nevertheless, we note that some methods have been proposed to convert measured $f(\mathrm{RH})$ to $\kappa$ (Kuang et al., 2017, 2018).

Single particle techniques (Krieger et al., 2012; Li et al., 2016) have provided physiochemical data which are very valuable to test aerosol thermodynamic models, largely helping us better understand tropospheric aerosol hygroscopicity. However, as the number of particles examined in single particle studies is very limited, these studies usually do not provide direct information on overall aerosol hygroscopicity in the ambient air and thus are not discussed herein. Although not covered in this review, remote sensing techniques can also be used to retrieve aerosol hygroscopicity in the troposphere (Lv et al., 2017; Bedoya-Velásquez et al., 2018; Tang et al., 2019; Dawson et al., 2020).

The first goal of this paper is to provide a comprehensive overview of the hygroscopic properties and $\mathrm{CCN}$ activities of tropospheric aerosols in China via a review of previous field studies. The second goal is to compile and present measurement data (as compiled in Tables S1-S5 in the Supplement) reported by previous works using a consistent framework (i.e., using the single hygroscopicity parameter) to enhance their accessibility and usability. The third goal, perhaps more importantly, is to identify knowledge gaps in this field and then to provide an outlook which can serve as practical guidelines for planning future research. In this paper, Sect. 2 describes the methodology adopted in this paper to analyze and review previous studies, and previous measurements of hygroscopic properties and CCN activities of tro- 
pospheric aerosols in China are reviewed and discussed in Sects. 3 and 4. At the end, Sect. 5 outlines knowledge gaps and research perspectives.

\section{Methodology}

\subsection{Hygroscopic properties}

H-TDMA instruments, initially developed $\sim 40$ years ago (Liu et al., 1978; McMurry et al., 1983; Rader and McMurry, 1986; McMurry and Stolzenburg, 1989), have been widely used in field and laboratory studies (Kreidenweis et al., 2005; Svenningsson et al., 2006; Gysel et al., 2007; Sjogren et al., 2008; Swietlicki et al., 2008; Duplissy et al., 2009; Asmi et al., 2010; Liu et al., 2011; Wu et al., 2011; Kreidenweis and Asa-Awuku, 2014; Zieger et al., 2017; Tang et al., 2019). Technical details of H-TDMA measurements, including operation principles, data analysis, etc., have been detailed in a review paper (Swietlicki et al., 2008). In brief, an aerosol flow, dried to $<20 \% \mathrm{RH}$, is passed through an aerosol neutralizer and the first differential mobility analyzer (DMA) to produce quasi-monodisperse aerosols with a given mobility diameter; after that, the aerosol flow is delivered through a humidifier to be humidified to a given $\mathrm{RH}$, and subsequently aerosol size distributions are measured using the second DMA coupled with a condensation particle counter (CPC). The hygroscopic growth factor (GF) is defined as the ratio of the aerosol mobility diameter at a given $\mathrm{RH}$ to that in dry conditions. As aerosol particles at a given size may have different hygroscopic properties and thus display different GF values at a given RH, probability distribution functions of GF (i.e., number fractions of aerosol particles at each GF) have also been reported in some studies.

The measured distribution functions of GF are usually smoothed and skewed due to several reasons; e.g., the finite width of the DMA's transfer function and several tandem differential mobility analyzer (TDMA) inversion algorithms have been proposed to convert the H-TDMA raw data to the probability density function of GF (Stolzenburg and McMurry, 1988; Stratmann et al., 1997; Voutilainen et al., 2000; Cocker et al., 2001; Cubison et al., 2005; Gysel et al., 2009). The algorithm developed by Gysel et al. (2009), TDMAinv, is currently the most widely used one. Errors and uncertainties of H-TDMA data can come from several sources, including RH and temperature variability, electrical mobility classification, particle nonequilibrium in the second DMA, etc. Swietlicki et al. (2008) comprehensively discussed the sources and magnitudes of these errors and how they can be reduced or minimized. In addition, guidelines used for $\mathrm{H}$ TDMA measurements, including instrumental design, calibration, validation, and operation, as well as data analysis, have been recommended in the literature (Duplissy et al., 2009; Massling et al., 2011).
H-TDMA measurements of ambient aerosols were typically conducted for a few different particle diameters at a given RH; most measurements were carried out at $90 \% \mathrm{RH}$, though some studies also reported GFs at other RHs. To facilitate the comparison of GFs reported at different RHs, we convert GF measured at a given RH to $\kappa$ using Eqs. (1)-(2) (Petters and Kreidenweis, 2007; Tang et al., 2016):

$$
\begin{aligned}
\kappa & =\left(\mathrm{GF}^{3}-1\right)\left(\frac{B}{\mathrm{RH}}-1\right), \\
B & =\exp \left(\frac{A}{d_{0} \cdot \mathrm{GF}}\right),
\end{aligned}
$$

where $d_{0}$ is the dry particle diameter; $A$, which describes the Kelvin effects, is equal to $2.1 \mathrm{~nm}$ at $298.15 \mathrm{~K}$ if the surface tension is assumed to be the same as water $\left(0.072 \mathrm{~J} \mathrm{~m}^{-2}\right)$ (Petters and Kreidenweis, 2007; Tang et al., 2016). Converting GF to $\kappa$ also facilitates the comparison between hygroscopic properties and CCN activities. For a few studies which reported GFs at different RHs, we focus GF measured at $90 \% \mathrm{RH}$; if the data at $90 \%$ are not available, we then choose measurements at the RH closest to $90 \%$.

To further facilitate the comparison between different measurements, Swietlicki et al. (2008) classified aerosol hygroscopicity into four groups according to their GF at $90 \%$ RH. This methodology was adopted by Ye et al. (2013) who reported aerosol hygroscopic growth measurements in Shanghai. Nevertheless, Ye et al. (2013) classified aerosol particles into three modes (instead of four), and the criteria used are slightly different from Swietlicki et al. (2008). Here we adopt the method proposed by Ye et al. (2013), who classified aerosol hygroscopicity into three modes, including the nearly hydrophobic $(\mathrm{NH}, \kappa<0.1)$, the less hygroscopic $(\mathrm{LH}$, $0.1<\kappa<0.25)$ and the more hygroscopic $(\mathrm{MH}, \kappa>0.25)$ modes. However, here a few further statements are necessary. First, terminologies used differ in previous studies for aerosol hygroscopicity modes. For example, bimodal aerosol hygroscopicity was frequently observed in China (as discussed in Sect. 3), and the nearly hydrophobic mode defined by Ye et al. (2013) was called the less hygroscopic mode or the low hygroscopic mode in several studies. Second, actual aerosol hygroscopicity in the troposphere may not perfectly fit into one of the three modes defined by Ye et al. (2013).

\subsection{CCN activities}

A variety of instruments have been developed to measure CCN number concentrations (Twomey, 1963; Sinnarwalla and Alofs, 1973; Fukuta and Saxena, 1979; Hudson, 1989; Ji et al., 1998; Chuang et al., 2000; McMurry, 2000; Nenes et al., 2001; Otto et al., 2002; VanReken et al., 2004; Roberts and Nenes, 2005; Frank et al., 2007; Kreidenweis and AsaAwuku, 2014). Currently, the most widely used one is the continuous-flow streamwise thermal gradient $\mathrm{CCN}$ counter based on the design of Roberts and Nenes (2005) and Lance et al. (2006) and commercialized by Droplet Measurement 
Technologies. Mode details of this instrument can be found elsewhere (Roberts and Nenes, 2005; Lance et al., 2006).

Measurements of size-resolved CCN activities have been discussed in a number of previous studies (Lance et al., 2006; Frank et al., 2007; Petters et al., 2007; Rose et al., 2008; Good et al., 2010; Moore et al., 2010; Rose et al., 2010; Bougiatioti et al., 2011). In many studies, an aerosol flow sampled from the ambient air, after being dried to $<20 \%$ $\mathrm{RH}$, is passed through an aerosol neutralizer and then a DMA to produce quasi-monodisperse aerosols. The aerosol flow is subsequently split into two flows: one flow is sampled into a $\mathrm{CCN}$ counter to measure number concentrations of cloud condensation nuclei ([CCN]), and the other one is sampled into a CPC to measure number concentrations of condensation nuclei $([\mathrm{CN}])$. At a given supersaturation, activation fractions $([\mathrm{CCN}] /[\mathrm{CN}])$ are measured as a function of particle diameter (selected using the DMA) and then fitted by an activation curve to determine the activation diameter at which the activation fraction is equal to 0.5 (Snider et al., 2006; Rose et al., 2008; Sullivan et al., 2009; Bougiatioti et al., 2011; Cerully et al., 2011). Activation fractions can be measured at one or more supersaturations as a function of particle diameter. Methods used for instrument calibration and data correction, which can be found in the literature (Frank et al., 2007; Petters et al., 2007; Rose et al., 2008; King et al., 2009; Petters et al., 2009; Moore et al., 2010), are not discussed herein. Furthermore, $\kappa$ can be derived from the determined activation diameter at a given supersaturation (Petters and Kreidenweis, 2007).

Maximum activation fractions may not approach one for ambient aerosols, and generally two methods have been used to fit the data. If the maximum activation fraction of the fitted activation curve is not fixed (three-parameter fit), the derived activation diameter $\left(d_{\mathrm{a}}\right)$ and single hygroscopicity parameter $\left(\kappa_{\mathrm{a}}\right)$ describe the average properties of activated particles; if it is forced to be 1 (two-parameter fit), the derived activation diameter $\left(d_{\mathrm{t}}\right)$ and single hygroscopicity parameter $\left(\kappa_{\mathrm{t}}\right)$ describe the overall properties of aerosol particles whose diameters do not exceed the maximum diameter scanned (Rose et al., 2010). For aerosols with a bimodal hygroscopicity distribution, $\kappa_{\mathrm{a}}$ is comparable to the $\kappa$ determined using H-TDMA for the more hygroscopic mode, while $\kappa_{\mathrm{t}}$ is comparable to the average $\kappa$ for the two modes. In addition to $d_{\mathrm{a}}$ and $d_{\mathrm{t}}$, the apparent cutoff diameter (above which $[\mathrm{CN}]$ is equal to [CCN] at a given supersaturation), $d_{\text {cut }}$ (and thus $\kappa_{\text {cut }}$ ) can be determined if it is assumed that particles at each size are internally mixed and that larger particles are activated first (Rose et al., 2010; Hung et al., 2014). The determination of $d_{\text {cut }}$ does not require size-resolved activation fractions, but needs the overall activation fractions and aerosol number size distribution (Burkart et al., 2011; Hung et al., 2014). Our review paper is focused on $\kappa_{\mathrm{a}}$ and to a lesser extent $\kappa_{\mathrm{t}}$ and only discusses $\kappa_{\text {cut }}$ when neither $\kappa_{\mathrm{a}}$ nor $\kappa_{\mathrm{t}}$ was reported.

In addition, $[\mathrm{CCN}]$ and $[\mathrm{CCN}] /[\mathrm{CN}]$ were also measured at one or more supersaturation in Tianjin (Deng et al., 2011;
Yang et al., 2012; Zhang et al., 2012), Zhangjiakou (Hebei) (Lu and Guo, 2012), Shijiazhuang (Hebei) (Lu and Guo, 2012), Xingtai (Hebei) (Y. Wang et al., 2018a), Qingdao (K. Li et al., 2015), Shanghai (Leng et al., 2013, 2014), Guangzhou (Duan et al., 2017, 2018), and Mt. Huang (Fang et al., 2016), as well as over marginal seas in China (Zhu et al., 2019; Gao et al., 2020) and the northwestern Pacific (J. Wang et al., 2019; Zhu et al., 2019). As these studies did not carry out size-resolved measurements and thus did not report critical diameters or $\kappa$, they are not further discussed herein.

\section{Hygroscopic growth}

A number of aerosol hygroscopic growth measurements have been carried out in China since 2001 using H-TDMA (or very similar instruments). Most of these measurements were performed in three regions with severe air pollution, including the North China Plain (NCP), Yangtze River Delta (YRD), and Pearl River Delta (PRD), and these studies are discussed in Sect. 3.1-3.3. In addition, as discussed in Sect. 3.4, several measurements were also conducted at other locations in eastern and southern China.

\subsection{North China Plain}

The North China Plain is a heavily polluted region where many aerosol hygroscopic growth measurements were conducted, as summarized in Table S1. In this section, we review the measurements carried out at urban sites in Beijing (Sect. 3.1.1), rural sites in Beijing (Sect. 3.1.2), other urban and suburban sites (Sect. 3.1.3), and other rural sites (Sect. 3.1.4).

\subsubsection{Urban sites in Beijing}

Aerosol hygroscopic growth has been measured at three urban sites in Beijing, including the Peking University (PKU) site, the Institute of Atmospheric Physics (IAP) site, and the Chinese Academy of Meteorological Sciences (CAMS) site.

\section{Peking University site}

The PKU site is located on the campus of Peking University $\left(39^{\circ} 59^{\prime} 20^{\prime \prime} \mathrm{N}, 116^{\circ} 18^{\prime} 26^{\prime \prime} \mathrm{E}\right)$, which is between the fourth and fifth ring road in the northwest of Beijing. All the measurements (Massling et al., 2009; Meier et al., 2009; Wu et al., 2016, 2017; Wang et al., 2018b) took place on the roof of a six-floor building ( $\sim 30 \mathrm{~m}$ above ground), which is $\sim 100 \mathrm{~m}$ away from a major road.

Aerosol hygroscopic growth was first measured at the PKU site during 2004-2005 (Massling et al., 2009; Meier et al., 2009). Massling et al. (2009) measured aerosol hygroscopic growth (at $90 \%$ RH) in June-July 2004 and JanuaryFebruary 2005. Aerosol hygroscopicity exhibited trimodal 
distribution, and $\kappa$ values were found to be in the range of 0 $0.028,0.036-0.176$, and $0.175-0.386$ for the low, medium, and high hygroscopic modes (Massling et al., 2009). In addition, no obvious difference in aerosol hygroscopicity was found between summer and winter because mass fractions of soluble inorganic species were similar in the two seasons at each individual particle size (Massling et al., 2009). Ammonium sulfate was the major inorganic species for the high hygroscopic mode, while fresh carbonaceous materials (e.g., soot) dominated the low hygroscopic mode (Massling et al., 2009). Aerosol hygroscopicity was found to increase with particle size and pollution levels (Massling et al., 2009) as more secondary inorganic species were formed.

Meier et al. (2009) further explored aerosol hygroscopic growth (at $90 \%$ RH) at the PKU site in January 2005. Similar to the work of Massling et al. (2009), three aerosol hygroscopicity modes were identified, with the $\kappa$ values being 0 $0.027,0.036-0.154$, and $0.152-0.366$ for low, medium, and high hygroscopic modes (Meier et al., 2009). However, no obvious dependence of aerosol hygroscopicity on air pollution levels was found as mass ratios of hydrophobic species to more hygroscopic species were similar under different pollution conditions. The average $\kappa$ values were found to first increase $(30-80 \mathrm{~nm})$ and then decrease $(80-350 \mathrm{~nm})$ with particle size due to increased fractions of carbonaceous species in the accumulation mode. Measured GFs at $90 \%$ RH were compared with these calculated from size-resolved inorganic compositions measured offline, and discrepancies between measured and calculated GFs were attributed to the effects of organics contained (Meier et al., 2009). In addition, hygroscopic growth at $55 \%$ and $70 \% \mathrm{RH}$ was also explored for 30-400 $\mathrm{nm}$ aerosol particles (Meier et al., 2009), and GF at $55 \%$ and $70 \% \mathrm{RH}$, compared to $90 \% \mathrm{RH}$, displayed similar dependence on particle size.

Wu et al. (2016, 2017) and Wang et al. (2018b) carried out extensive aerosol hygroscopic growth measurements (at $90 \% \mathrm{RH}$ ) at the PKU site during 2014-2015. Bimodal aerosol hygroscopicity distribution was observed in MayJune 2014 (Wu et al., 2016), dominated by the hydrophilic mode, and the average $\kappa$ values appeared to increase with particle size from 0.160 at $50 \mathrm{~nm}$ to 0.280 at $250 \mathrm{~nm}$. In addition, number fractions of aerosol particles in the hydrophilic mode first increased with particle size up to $150 \mathrm{~nm}$ and then did not show significant change with further increase in particle size (Wu et al., 2016); to be more specific, average number fractions of aerosol particles in the hydrophilic mode were $\sim 0.6$ at $50 \mathrm{~nm}$ and increased to $\sim 0.8$ above $150 \mathrm{~nm}$. For each particle size, aerosol hygroscopicity was found to be larger during new particle formation (NPF) periods compared to non-NPF periods (Wu et al., 2016) because more secondary species were found during NPF periods typically associated with strong photochemical processes. Aerosol mass spectrometry (AMS) measurements suggested that aerosol hygroscopicity was dominated by inorganics, the contribution of which increased with particle size and pollu-

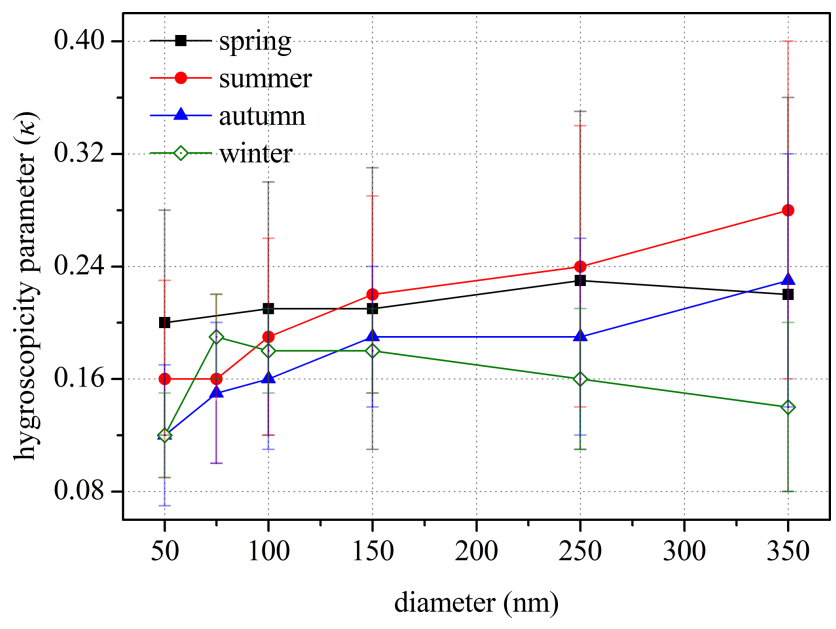

Figure 1. Change in average $\kappa$ with aerosol diameter at the PKU site in four different seasons between May 2014 and January 2015 (Wang et al., 2018b).

tion levels (Wu et al., 2016). The measured $\kappa$ values could be predicted well using the AMS data, and a linear relationship was found between the derived $\kappa$ values of organics and their $\mathrm{O}: \mathrm{C}$ ratios (Wu et al., 2016).

The PKU site was affected by a series of biomass burning events in May-June 2014, and the effect of biomass burning on aerosol composition and hygroscopicity was examined (Wu et al., 2017). During biomass burning events, biomass burning contributed significantly to the production and growth of aerosols in the Aitken mode, and the contribution of organics and black carbon to mass concentrations of submicrometer aerosols reached $60 \%$ and $18 \%$ (Wu et al., 2017). Hygroscopicity and number fractions of aerosols in the hydrophobic mode were relatively invariable during biomass burning events, and the average $\kappa$ values, which showed no variation with particle size $(50-250 \mathrm{~nm})$, were determined to be $\sim 0.1$ (Wu et al., 2017), substantially smaller than those in the same period without significant impacts from biomass burning (Wu et al., 2016).

Seasonal variation of aerosol hygroscopic growth was investigated at the PKU site from May 2014 to January 2015 (Wang et al., 2018b), and the result is displayed in Fig. 1. Average $\kappa$ values increased significantly with particle size (50$350 \mathrm{~nm}$ ) in summer and autumn, when strong photochemical processes enhanced secondary aerosol formation and led to particle growth (Wang et al., 2018b); in fact, number fractions of particles in the hydrophilic mode increased with pollution levels, and they dominated the accumulation mode when $\mathrm{PM}_{2.5}$ mass concentration exceeded $100 \mu \mathrm{g} \mathrm{m}^{-3}$. In contrast, as shown in Fig. 1, average $\kappa$ values only increased slightly with particle size $(50-350 \mathrm{~nm})$ in spring, while it decreased substantially with particle size $(75-350 \mathrm{~nm})$ in winter (Wang et al., 2018b), indicating the significant contribution of primary species to aerosol particles. Furthermore, be- 
ing different to summer and autumn, substantial amounts of aerosol particles in the hydrophobic mode were always observed in spring and winter (Wang et al., 2018b). Another important feature revealed by Fig. 1 is that for $150-350 \mathrm{~nm}$ aerosols, the hygroscopicity was always highest in summer and lowest in winter (Wang et al., 2018b), and the difference between the two seasons increased with particle size. The difference in aerosol hygroscopicity between summer and winter may be caused by enhanced photochemical processes in the summer and, as a result, by increased fractions of secondary species.

In addition, aerosol hygroscopic growth was investigated in March-April 2015 on the roof of the Environmental Science Building $\left(40^{\circ} 0^{\prime} 17^{\prime \prime} \mathrm{N}, 116^{\circ} 19^{\prime} 34^{\prime \prime} \mathrm{E}\right)$ on the campus of Tsinghua University (Fajardo et al., 2016). This site, very close to the PKU site, is usually affected by the same air masses. Number size distributions under dry and ambient conditions were measured for $10-500 \mathrm{~nm}$ particles to explore aerosol hygroscopicity under ambient RH (Fajardo et al., 2016). No obvious aerosol growth was observed for RH below $50 \%$ (Fajardo et al., 2016); however, the aerosol volume was increased by $\sim 80 \%$ when RH reached $50 \%$, and a further increase in ambient RH led to further hygroscopic growth.

\section{IAP site}

The IAP site is located at the Institute of Atmospheric Physics, Chinese Academy of Science (39.97 $\left.{ }^{\circ} \mathrm{N}, 116.37^{\circ} \mathrm{E}\right)$ between the third and fourth ring roads in northern Beijing. All the aerosol hygroscopic growth measurements (Y. Wang et al., 2017b, 2019; Fan et al., 2020; Jin et al., 2020) were conducted at $90 \% \mathrm{RH}$ at ground level.

Y. Wang et al. (2017b) investigated aerosol hygroscopic growth at the IAP site in August-October 2015 when emission control measures were implemented for the 2015 China Victory Day parade. Three periods with different pollution levels, including the control clean $(\mathrm{C} 1)$, the non-control clean (C2), and the non-control polluted (P) periods, were specifically examined to evaluate the effect of emission control. Figure 2 shows that aerosol hygroscopicity increased with particle size and pollution level because mass fractions of hydrophilic species, such as sulfate, nitrate, and oxidized organics, increased with particle size (Y. Wang et al., 2017b), especially under highly polluted conditions. For example, $\kappa$ values increased from $0.100 \pm 0.05$ at $40 \mathrm{~nm}$ to $0.250 \pm$ 0.120 at $200 \mathrm{~nm}$ during $\mathrm{C} 1$, from $0.140 \pm 0.060$ at $40 \mathrm{~nm}$ to $0.280 \pm 0.130$ at $200 \mathrm{~nm}$ during $\mathrm{C} 2$, and from $0.160 \pm 0.080$ at $40 \mathrm{~nm}$ to $0.420 \pm 0.120$ at $200 \mathrm{~nm}$ during the polluted period (Y. Wang et al., 2017b). Furthermore, number fractions of particles in the more hygroscopic mode increased in the polluted period compared to $\mathrm{C} 1$ and $\mathrm{C} 2$. For $40 \mathrm{~nm}$ particles, a quasi-unimodal hygroscopicity distribution was observed during $\mathrm{C} 1$, while bimodal or quasi-trimodal distributions were observed during the other two periods; in contrast,

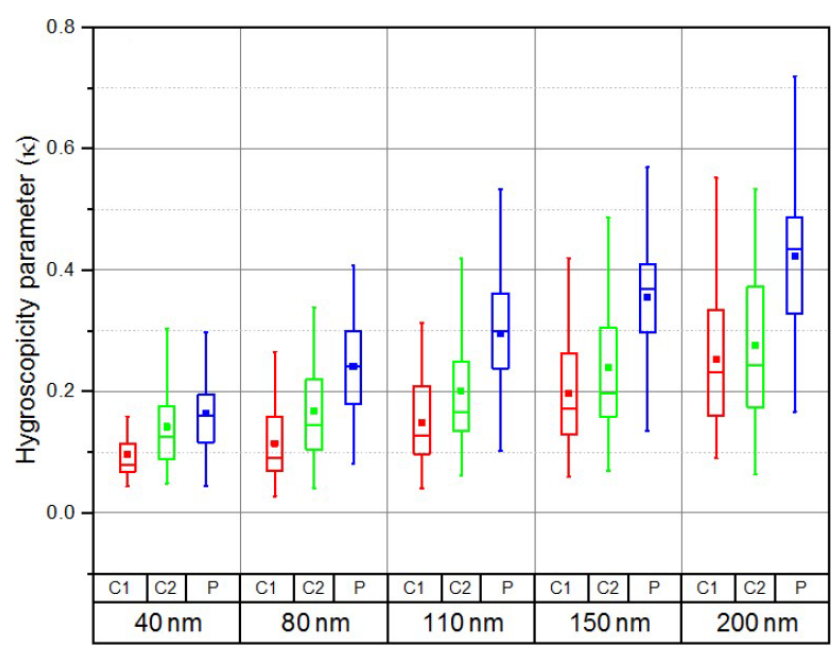

Figure 2. Size-resolved $\kappa$ during the control clean $(\mathrm{C} 1)$, the noncontrol clean (C2), and the non-control polluted (P) periods. Solid squares represent the average $\kappa$, boxes represent the 25 th, 50th, and 75 th percentiles, and extremities represent the 5 th and 95 th percentiles. Reprint with permission by Y. Wang et al. (2017b).

bimodal patterns were always observed for $150 \mathrm{~nm}$ particles (Y. Wang et al., 2017b). It was also found that for all the three periods, the average $\kappa$ values were always larger during the daytime than the nighttime (Y. Wang et al., 2017b) as aerosol particles were more aged due to strong photochemical processes in daytime.

A following study (Y. Wang et al., 2019) measured aerosol hygroscopic growth at the IAP site in November-December 2016. Overall, the average $\kappa$ values were found to increase with particle size from 0.164 at $40 \mathrm{~nm}$ to 0.230 at $200 \mathrm{~nm}$ during the clean period and from 0.155 at $40 \mathrm{~nm}$ to 0.290 at $200 \mathrm{~nm}$ during the polluted period (Y. Wang et al., 2019); compared to the clean period, the average $\kappa$ values during the polluted period were smaller for $40 \mathrm{~nm}$ particles but larger for $80-200 \mathrm{~nm}$ particles. In addition, bimodal distributions were always observed (Y. Wang et al., 2019). Number fractions of particles in the less hygroscopic mode were larger for $40 \mathrm{~nm}$ particles and smaller for $80-200 \mathrm{~nm}$ particles during the polluted period (Y. Wang et al., 2019) when compared to the clean period, reflecting the compositional variation in 40 and $80-200 \mathrm{~nm}$ particles during the two periods. Diurnal variation of aerosol hygroscopicity was also explored, which displayed significant differences between clean and polluted periods (Y. Wang et al., 2019). To be more specific, the average $\kappa$ values of $40 \mathrm{~nm}$ particles increased in daytime during clean periods due to strong photochemical reactions, while they showed a reverse pattern during polluted periods due to the dominant contribution by primary emissions. For $150 \mathrm{~nm}$ particles, average $\kappa$ values showed similar diurnal variations for clean and polluted periods, reaching maximum values at noon. 
Jin et al. (2020) further analyzed size-resolved aerosol composition and hygroscopicity measured at the IAP site in November-December 2016 (Y. Wang et al., 2019). The sizedependent $\kappa$ values derived from measured GF at $90 \% \mathrm{RH}$ were used to calculate ALWC at ambient RH, assuming that a constant $\kappa$ could be used to calculate GF at different RHs (Jin et al., 2020); in addition, size-resolved aerosol composition measured using AMS was used as input in ISORROPIA-II to simulate ALWC at ambient RH. ALWC simulated using ISORROPIA-II was found to be significantly smaller than calculated ALWC when RH was $<60 \%$ (Jin et al., 2020) because ISORROPIA-II failed to estimate water uptake by organics at low RH. Overall, organic materials were estimated to contribute to $30 \pm 22 \%$ of ALWC (Jin et al., 2020), highlighting the importance of organics to aerosol hygroscopicity in urban Beijing.

Fan et al. (2020) further conducted aerosol hygroscopic growth measurements at the IAP site in May-June 2017, and bimodal hygroscopicity distributions were also observed for 40-200 nm aerosols. The summertime measurement in 2017 was compared with the wintertime measurement at the same site in 2016 (Y. Wang et al., 2019), and the size dependence of aerosol hygroscopicity was found to differ for the two seasons (Fan et al., 2020). The average $\kappa$ values increased from 0.158 at $40 \mathrm{~nm}$ to 0.271 at $110 \mathrm{~nm}$ in winter, and a further increase in particle size (to $200 \mathrm{~nm}$ ) led to slight decrease in $\kappa$ because mass fractions of secondary inorganic species decreased slightly from $61.8 \%$ at $110 \mathrm{~nm}$ to $59.3 \%$ at $200 \mathrm{~nm}$ (Fan et al., 2020). For comparison, the average $\kappa$ values increased with particle size in summer, from 0.211 at $40 \mathrm{~nm}$ to 0.267 at $200 \mathrm{~nm}$, as mass fractions of secondary inorganic species increased from $56.7 \%$ at $80 \mathrm{~nm}$ to $63.0 \%$ at $200 \mathrm{~nm}$ (Y. Wang et al., 2019; Fan et al., 2020). It was suggested that the size dependence of aerosol hygroscopicity was mainly determined by the size-resolved mass fractions of secondary inorganic species (Fan et al., 2020).

\section{CAMS site}

X. Wang et al. (2018) measured aerosol hygroscopic growth (30\%-90\% RH) of ambient aerosols on the campus of the Chinese Academy of Meteorological Sciences located between the second and third ring roads in western Beijing. Measurements were conducted on a building roof $(\sim 53 \mathrm{~m}$ above ground level) in December 2016, and the distance between the site and a major road with heavy traffic was $<200 \mathrm{~m}$. Aerosol hygroscopic growth displayed unimodal distributions when $\mathrm{RH}$ did not exceed $60 \%$, while bimodal distributions were usually observed at $70 \%$ and $80 \% \mathrm{RH}$; in addition, aerosol hygroscopic growth occasionally exhibited trimodal distribution at $85 \%$ and $90 \% \mathrm{RH}$ (X. Wang et al., 2018). Measured GFs at $90 \% \mathrm{RH}$ were used to calculate $\kappa$, which were determined to be $0.010-0.015$ and $0.286-$ 0.358 for the hydrophobic and hydrophilic modes (X. Wang et al., 2018), both increasing with particle size (50-200 nm).
Number fractions of hydrophobic particles exceeded $50 \%$ at 50 and $100 \mathrm{~nm}$, while hydrophilic particles frequently became dominant in terms of number concentrations at 150 and $200 \mathrm{~nm}$ (X. Wang et al., 2018). In addition, hygroscopicity decreased at $50 \mathrm{~nm}$ but increased at $200 \mathrm{~nm}$ during heavily polluted periods (X. Wang et al., 2018) when the contribution of primary emissions from local traffic to smaller particles $(20$ and $100 \mathrm{~nm}$ ) increased, while the fractions of secondary inorganic species increased for larger particles (150 and $200 \mathrm{~nm}$ ).

\subsubsection{Rural sites in Beijing}

Aerosol hygroscopic growth was measured at two rural sites in Beijing, including Yufa (Achtert et al., 2009) and Huairou (Y. Wang et al., 2020). The Yufa site $\left(39.51^{\circ} \mathrm{N}, 116.31^{\circ} \mathrm{E}\right)$ is $\sim 1.2 \mathrm{~km}$ away from a high-traffic expressway and $\sim 50 \mathrm{~km}$ south of urban Beijing, and it can be considered a representative rural and regional background site. Achtert et al. (2009) measured aerosol hygroscopic growth as a function of $\mathrm{RH}$ $(56 \%, 76 \%, 85 \%$, and $91 \%)$ on a four-floor building $(22 \mathrm{~m}$ above the ground) at this site in August-September 2006. GFs at $91 \% \mathrm{RH}$, ranging from 1.15 to 1.80 for $30-300 \mathrm{~nm}$ particles, were found to be larger in the accumulation mode than the Aitken mode (Achtert et al., 2009); furthermore, an increase in mass fractions of sulfate during polluted periods led to an increase in aerosol hygroscopicity with pollution level. Diurnal variation of aerosol hygroscopicity was also explored (Achtert et al., 2009); hygroscopicity was found to be higher in the daytime than the nighttime for the Aitken mode, whereas no significant difference in hygroscopicity was observed between daytime and nighttime for the accumulation mode.

The Huairou site $\left(40.42^{\circ} \mathrm{N}, 116.69^{\circ} \mathrm{E}\right)$ is located on the campus of the University of the Chinese Academy of Sciences, $\sim 60 \mathrm{~km}$ northeast of the center of Beijing. It was mainly influenced by regional transport of pollutants from downtown Beijing (Tan et al., 2018) and small local sources nearby (e.g., moderate traffic and small residential areas). Aerosol hygroscopic growth (at $90 \% \mathrm{RH}$ ) was measured at this site in January-March 2016 (Y. Wang et al., 2020). The average $\kappa$ values were determined to be $0.162-0.208$ for 50 $300 \mathrm{~nm}$ particles (Y. Wang et al., 2020), and mass fractions of nitrate, which contributed significantly to aerosol hygroscopic growth, reached $44 \%$ during polluted episodes.

\subsubsection{Other urban and suburban sites}

Aerosol hygroscopic growth was measured at other four urban and suburban sites in NCP, including two sites in Tianjin, one site in Hebei Province, and one site in Shanxi Province.

\section{Tianjin}

The Wuqing site is located next to the Wuqing Meteorological Station $\left(39^{\circ} 23^{\prime} \mathrm{N}, 117^{\circ} 0^{\prime} \mathrm{E}\right)$ in the western area of 
Wuqing (Tianjin), surrounded by mixed agricultural, residential, and industrial regions. This site is a good place to study regional air pollution in NCP as it is $\sim 30 \mathrm{~km}$ northwest of urban Tianjin, $\sim 80 \mathrm{~km}$ southeast of urban Beijing, $\sim 130 \mathrm{~km}$ southwest of Tangshan (Hebei), and $\sim 160 \mathrm{~km}$ northeast of Baoding (Hebei). Aerosol hygroscopic growth was measured at three RHs $(90 \%, 95 \%$, and $98.5 \%)$ at this site in July-August 2009 (Liu et al., 2011). Bimodal hygroscopicity distribution, with a dominant more hygroscopic mode and a smaller nearly hydrophobic mode, was observed over the whole period, and the average $\kappa$ values, derived from GF measured at $90 \% \mathrm{RH}$, increased from 0.250 at $50 \mathrm{~nm}$ to 0.340 at $250 \mathrm{~nm}$ as number fractions of aerosol particles in the more hygroscopic mode increased with particle size (from $68 \%$ for $50 \mathrm{~nm}$ to $85 \%$ for $250 \mathrm{~nm}$ ) (Liu et al., 2011). Compared to the nighttime, both the average $\kappa$ values and number fractions of particles in the more hygroscopic mode were larger during the daytime (Liu et al., 2011) because photochemical processes during the daytime led to the enhanced formation of secondary species in aerosol particles and thus an increase in their hygroscopicity. The average $\kappa$ values were found to increase with particle size for the more hygroscopic mode from 0.310 at $50 \mathrm{~nm}$ to 0.390 at $250 \mathrm{~nm}$ (Liu et al., 2011); in contrast, they decreased with particle size for the nearly hydrophobic mode from 0.054 at $50 \mathrm{~nm}$ to 0.025 at $250 \mathrm{~nm}$. It was found that secondary inorganic species increased the hygroscopicity of the accumulation mode, while organics decreased the hygroscopicity of the Aitken mode (Liu et al., 2014). In addition, $\kappa$ values calculated from aerosol compositions measured offline were consistent with those derived from H-TDMA measurements (Liu et al., 2014).

Two different methods were used to estimate ALWC at the Wuqing site in July-August 2009 (Bian et al., 2014). For the first method, $\kappa$ values derived from GF measurements at $90 \%-98.5 \% \mathrm{RH}$ were assumed to be constant at different RHs, and thus ALWC could be calculated from particle number size distribution (Bian et al., 2014); for the second method, size-resolved aerosol composition, only taking into account water soluble inorganic ions, was used as input in ISORROPIA-II to predict ALWC. ALWC estimated using the first method agreed with those using the second method for $>60 \% \mathrm{RH}$, but it was much larger compared to the second method when ambient RH was $<60 \%$ (Bian et al., 2014), suggesting that ISORROPIA-II was not capable of predicting ALWC at low RH.

In March 2018, Ding et al. (2019) carried out aerosol hygroscopic growth measurements $(70 \%-85 \% \mathrm{RH})$ at the NKU site, an air quality research supersite at Nankai University $\left(38^{\circ} 59^{\prime} \mathrm{N}, 117^{\circ} 20^{\prime} \mathrm{E}\right)$, which is $\sim 20 \mathrm{~km}$ away from downtown Tianjin. GFs measured at $85 \% \mathrm{RH}$ were used to calculate average $\kappa$ values, being $0.301-0.477,0.203-0.386$, and 0.281-0.419 on 13, 14, and 15 March (Ding et al., 2019). In addition, the average $\kappa$ values were found to be larger during polluted periods than clean periods as the contribu-
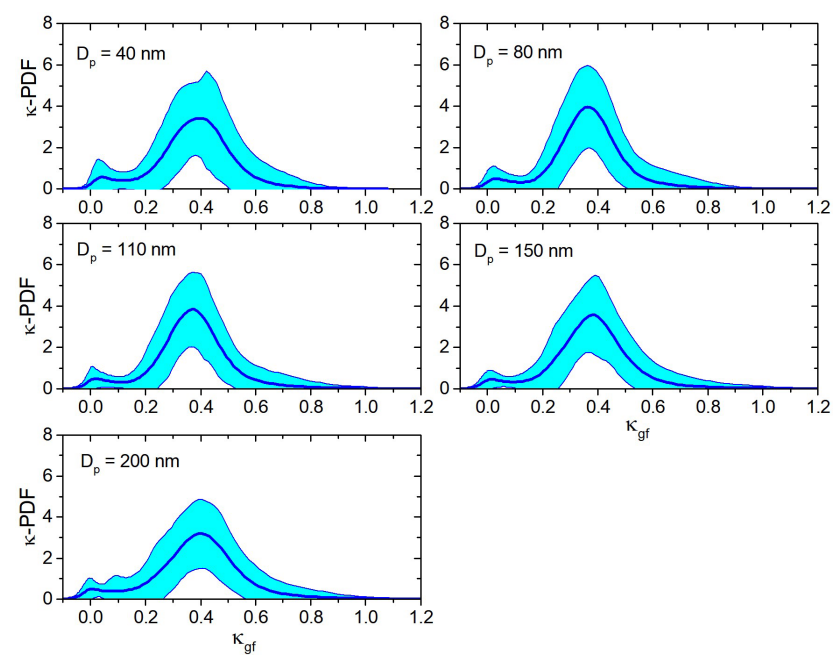

Figure 3. Mean probability density functions of $\kappa$ and their standard deviations (shaded areas) for 40, 80,110, 150, and $200 \mathrm{~nm}$ particles at the Xingtai site in May-June 2016, as derived from measured GF at $85 \%$ RH. Reprint with permission by Y. Wang et al. (2018a).

tion of nitrate, sulfate, and ammonium in the accumulation mode increased during polluted periods (Ding et al., 2019). It was also found that for the accumulation mode, $\kappa$ values were larger in the nighttime than the daytime (Ding et al., 2019) as an increase in RH during the nighttime led to the enhanced formation of sulfate and nitrate from aqueous oxidations of $\mathrm{SO}_{2}$ and heterogeneous hydrolysis of $\mathrm{N}_{2} \mathrm{O}_{5}$ (H. Wang et al., 2017). Water-soluble inorganic ions measured offline were used as input in ISORROPIA-II to predict aerosol hygroscopicity, and measured and predicted $\kappa$ values showed good agreement (Ding et al., 2019), implying that the contribution of organics to aerosol hygroscopic growth was quite limited during their campaign.

\section{Hebei Province}

The Xingtai site is located at the National Meteorological Basic Station in Xingtai $\left(37.18^{\circ} \mathrm{N}, 114.37^{\circ} \mathrm{E}\right)$, a heavily polluted city in the center of NCP, and aerosol hygroscopic growth (at $85 \% \mathrm{RH}$ ) was measured at this site in MayJune 2016 (Y. Wang et al., 2018a). As shown in Fig. 3, quasi-unimodal aerosol hygroscopicity distribution was observed, and number fractions of particles in the more hygroscopic mode were $\sim 90 \%$ for $40-200 \mathrm{~nm}$ particles (Y. Wang et al., 2018a), indicating that they were highly aged and internally mixed. As a result, the average $\kappa$ values were found to be 0.364-0.39 (Y. Wang et al., 2018a), significantly larger than those reported for most of the other sites in NCP. No obvious dependence of average $\kappa$ values on particle size was observed, and the average $\kappa$ values were found to be larger in daytime than nighttime, especially during new particle formation events. 
For the campaign at the Xingtai site in May-June 2016 (Y. Wang et al., 2018a), aerosol hygroscopicity on a clean day (21 May) was compared with that on a highly polluted day (23 May). Aerosol hygroscopicity was higher on the polluted day (Chen et al., 2019), likely due to the enhanced formation of nitrate as revealed by aerosol chemical speciation monitor (ACSM) measurements. Furthermore, aerosol hygroscopicity increased with particle size $(40-200 \mathrm{~nm})$ on both days, with average $\kappa$ values increasing from 0.288 to 0.339 on 21 May and from 0.325 to 0.352 on 23 May (Chen et al., 2019).

\section{Shanxi Province}

The Xinzhou site $\left(38.24^{\circ} \mathrm{N}, 112.43^{\circ} \mathrm{E}, 1500 \mathrm{~m}\right.$ above sea level) is located on the border between the NCP and the Loess Plateau. This suburban and regional site, surrounded by agricultural land with limited local anthropogenic emissions, is located $\sim 360 \mathrm{~km}$ southwest of Beijing, $\sim 78 \mathrm{~km}$ northwest of Taiyuan, and $\sim 10 \mathrm{~km}$ south of the city nearby. Aerosol hygroscopic growth $(85 \% \mathrm{RH})$ was investigated for 25-200 nm aerosols at this site in July-August 2014 (Zhang et al., 2017). Quasi-unimodal aerosol hygroscopicity distribution was observed, indicating highly aged and internally mixed particles. The average $\kappa$ values were determined to be $0.420-0.528$, significantly larger than those observed at other sites in the NCP; in addition, no obvious dependence of $\kappa$ on particle size was found (Zhang et al., 2017). This was because aerosols observed at this site were highly aged and well internally mixed after regional transport.

\subsubsection{Other rural sites}

Aerosol hygroscopic growth was measured at other two rural sites in NCP, i.e., the Xianghe site and the Wangdu site (both in Hebei). The Xianghe site $\left(39.75^{\circ} \mathrm{N}, 116.96^{\circ} \mathrm{E}\right)$, surrounded by residential areas and farmlands, is considered a typical rural site in NCP and is located $\sim 5 \mathrm{~km}$ west of the center of Xianghe town and $\sim 70 \mathrm{~km}$ southeast of Beijing. At this site, aerosol hygroscopic growth (at $87 \% \mathrm{RH}$ ) was measured in July-August 2013 (S. L. Zhang et al., 2016). Trimodal aerosol hygroscopicity distributions were observed for 50-350 nm particles (S. L. Zhang et al., 2016), and the average $\kappa$ values were determined to be $0.020-0.056,0.170$ 0.211 , and $0.365-0.455$ for nearly hydrophobic, less hygroscopic, and more hygroscopic modes. Aerosol hygroscopicity showed some dependence on air masses (S. L. Zhang et al., 2016); air masses which were transported from the north with high speed winds typically contained larger number fractions of hydrophobic species and exhibited lower hygroscopicity, whereas no obvious difference in aerosol hygroscopicity and mixing state was observed for other air masses.

The Wangdu site $\left(38.71^{\circ} \mathrm{N}, 115.16^{\circ} \mathrm{E}\right)$, a rural site located in the central area of NCP, is $\sim 200 \mathrm{~km}$ southwest of Beijing, and aerosol hygroscopic growth (at $90 \% \mathrm{RH}$ ) was measured at this site in June 2014 (Y. Wang et al., 2017a). Bimodal aerosol hygroscopicity distribution was always observed (Y. Wang et al., 2017a), indicating that aerosol particles were externally mixed. As larger particles contain higher mass fractions of secondary inorganic species, the average $\kappa$ values were found to increase with particle size from 0.240 at $30 \mathrm{~nm}$ to 0.320 at $250 \mathrm{~nm}$.

\subsection{Yangtze River Delta}

A number of aerosol hygroscopic growth measurements have been carried out since 2009 in three large cities (Shanghai, Hangzhou, and Nanjing) in the Yangtze River Delta.

\subsubsection{Shanghai}

Ambient aerosol hygroscopic growth was measured at two sites in Shanghai (Ye et al., 2011, 2013; Wang et al., 2014; Xie et al., 2017; Li et al., 2018; X. Wang et al., 2020). The FDU site $\left(31^{\circ} 18^{\prime} \mathrm{N}, 121^{\circ} 29^{\prime} \mathrm{E}\right)$ is located on the building roof of Department of Environmental Science and Engineering, Fudan University; the Pudong site $\left(31.22^{\circ} \mathrm{N}, 121.55^{\circ} \mathrm{E}\right)$ is located at the Pudong Meteorological Bureau. Both sites are considered urban sites surrounded by residential, industrial, and traffic areas, and their distance apart is $<10 \mathrm{~km}$.

\section{FDU site}

At the FDU site, Ye et al. (2011) measured aerosol hygroscopic growth $(30-200 \mathrm{~nm})$ at $20 \%-85 \%$ RH in JanuaryFebruary 2009. Bimodal hygroscopic growth distribution was always observed at $85 \% \mathrm{RH}$, and $\kappa$ values derived from measured GF at $85 \% \mathrm{RH}$ were determined to be $0.027-$ 0.063 and $0.291-0.381$ for the less and more hygroscopic modes (Ye et al., 2011). The average $\kappa$ values decreased with particle size for the less hygroscopic mode, while they increased with particle size for the more hygroscopic mode (Ye et al., 2011); in addition, number fractions of particles in the less hygroscopic mode decreased with particle size. The change in GF with RH $(20 \%-85 \%)$ was also discussed for particles with different sizes (Ye et al., 2011).

Compositional data provided by ATOFMS (aerosol timeof-flight mass spectrometry) were used to interpret GF measured at $85 \% \mathrm{RH}$ for $250 \mathrm{~nm}$ particles on 18-19 January and 10 February 2009 (Ye et al., 2011). Bimodal aerosol hygroscopicity distribution was observed for $250 \mathrm{~nm}$ particles, including a nearly hydrophobic mode with $\kappa$ values of 0.029-0.061 and a more hygroscopic mode with $\kappa$ values of $0.387-0.399$ (Wang et al., 2014). Aerosols in the more hygroscopic mode consisted predominantly of secondary species (e.g., organic carbon-amine, sulfate, and nitrate), while biomass burning aerosols, uncoated elemental carbon (EC), secondary organic compounds, and dust/ash were frequently identified in the nearly hydrophobic mode (Wang et al., 2014). 
Aerosol hygroscopic growth (at $85 \% \mathrm{RH}$ ) was also measured at this site in February-March 2014 (X. Wang et al., 2020). Aerosol hygroscopicity was found to exhibit a bimodal distribution at $250 \mathrm{~nm}$, and the average $\kappa$ values were determined to be 0.029 and 0.376 for nearly hydrophobic and more hydrophilic modes (X. Wang et al., 2020). Nearly hydrophobic particles typically included biomass burning aerosol, fresh EC, and high molecular mass organic carbon, while more hydrophilic particles included aged EC, amine-rich particles, etc. (X. Wang et al., 2020). Furthermore, a statistic method was developed to estimate aerosol hygroscopicity from single particle mass spectra (X. Wang et al., 2020).

Xie et al. (2017) further measured aerosol hygroscopic growth $(83 \% \mathrm{RH})$ at the FDU site in December 2014January 2015 . The bimodal aerosol hygroscopicity distribution (nearly hydrophobic and more hygroscopic modes) was usually observed, and the average $\kappa$ values increased from 0.161 at $40 \mathrm{~nm}$ to 0.345 at $400 \mathrm{~nm}$ (Xie et al., 2017). Number fractions of nearly hydrophobic particles increased during polluted periods for all the sizes considered $(40-400 \mathrm{~nm})$, indicating the significant contribution of primary particles during haze events (Xie et al., 2017); however, the increase in number fractions of nearly hydrophobic particles during pollution events was less significant for larger particles, suggesting that primary emissions contributed more to smaller particles.

Mixing state and hygroscopic growth (at $85 \% \mathrm{RH}$ ) were explored at the FDU site in July 2017 specifically for ambient black carbon (BC) aerosols (120, 240, and $260 \mathrm{~nm}$ ) (Li et al., 2018). Number fractions of BC particles decreased with particle size from $\sim 80 \%$ for $120 \mathrm{~nm}$ to $\sim 60 \%$ for $360 \mathrm{~nm}$. The hygroscopicity of BC particles displayed unimodal distribution, and their GF at $85 \% \mathrm{RH}$ peaked at $\sim 1.0$ (Li et al., 2018). The enhancement in hygroscopicity of BC particles due to their aging via condensation of secondary species was frequently observed (Li et al., 2018); during nighttime, nitrate contributed significantly to $\mathrm{BC}$ aging, while the formation of secondary organic materials played an important role during the daytime.

\section{Pudong site}

Aerosol hygroscopic growth (at $91 \% \mathrm{RH}$ ) was studied at the Pudong site in September 2009 (Ye et al., 2013). As shown in Fig. 4, aerosol hygroscopicity was found to be trimodal, including a nearly hydrophobic mode and a more hygroscopic mode, as well as a less hygroscopic mode with much less abundance (Ye et al., 2013), implying that these aerosols were externally mixed. The average $\kappa$ values increased from 0.270 at $30 \mathrm{~nm}$ to 0.390 at $200 \mathrm{~nm}$ for the more hygroscopic mode because mass fractions of secondary inorganic species increased with particle size (Ye et al., 2013). In contrast, the average $\kappa$ values decreased from 0.054 at $30 \mathrm{~nm}$ to 0.011 at $200 \mathrm{~nm}$ for the nearly hydrophobic mode.

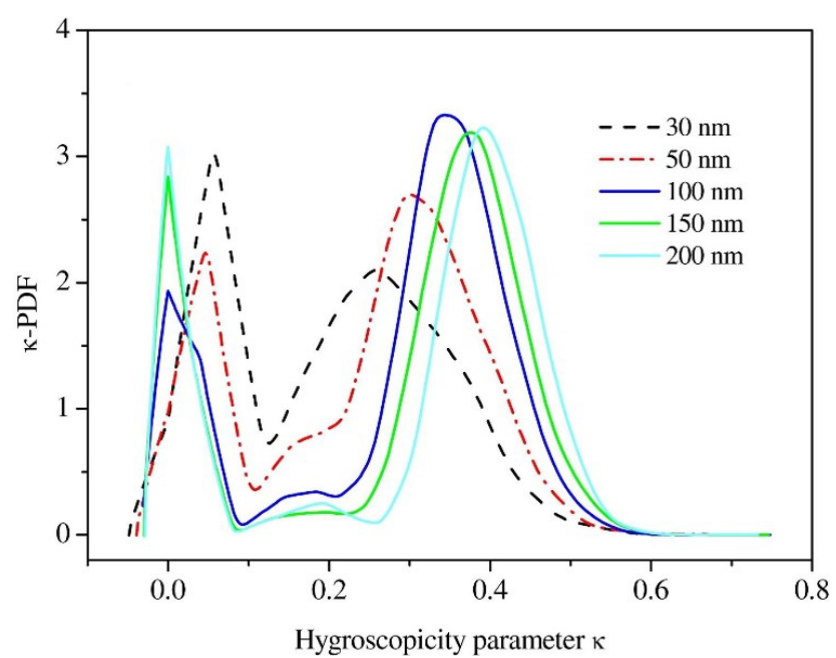

Figure 4. Probability distribution functions of the hygroscopicity parameter $(\kappa)$ for $30,50,100,150$ and $200 \mathrm{~nm}$ aerosols at the Pudong site in September 2009. Reprint with permission by Ye et al. (2013). Copyright 2013 Elsevier Ltd.

\subsubsection{Hangzhou}

Up to now, only one aerosol hygroscopic growth study was carried out in Hangzhou, at the ZJU site located on the Huajiachi campus of Zhejiang University $\left(30^{\circ} 16^{\prime} \mathrm{N}, 120^{\circ} 11^{\prime} \mathrm{E}\right)$. Aerosol hygroscopic growth was measured at $70 \%-90 \% \mathrm{RH}$ (mainly at 82\%) in December 2009-January 2010 (Zhang et al., 2011). Bimodal hygroscopicity distribution was observed for 50-200 nm aerosols, while unimodal hygroscopicity distribution was observed for $30 \mathrm{~nm}$ aerosols (Zhang et al., 2011). The average $\kappa$ values decreased from 0.121 at $30 \mathrm{~nm}$ to 0.065 at $80 \mathrm{~nm}$ for the low hygroscopic mode, and a further increase in particle size (up to $200 \mathrm{~nm}$ ) did not lead to significant change in $\kappa$ values (Zhang et al., 2011). For comparison, the average $\kappa$ values increased from 0.303 at $30 \mathrm{~nm}$ to 0.343 at $80 \mathrm{~nm}$ for the more hygroscopic mode, and a further increase in particle size only resulted in a very small increase in $\kappa$ values. In addition, number fractions of particles in the more hygroscopic mode increased from $\sim 48 \%$ for $30 \mathrm{~nm}$ to $\sim 70 \%$ for $100 \mathrm{~nm}$ and remained nearly constant for 100-200 nm (Zhang et al., 2011).

\subsubsection{Nanjing}

Aerosol hygroscopic growth was measured at three urban and suburban sites in Nanjing. The Nanjing University of Information Science and Technology (NUIST) site $\left(32^{\circ} 207^{\prime} \mathrm{N}\right.$, $118^{\circ} 717^{\prime} \mathrm{E}$ ) is a suburban site located on the 12th floor of the meteorological building at the Nanjing University of Information Science and Technology with several large petrochemical factories and a busy expressway nearby. The NATC site $\left(32.0^{\circ} \mathrm{N}, 118.7^{\circ} \mathrm{E}\right)$ is a typical urban site at Nanjing Advanced Technical College, located in the central business dis- 
trict with heavy residential and traffic emissions. The JEMC site is an urban site on the sixth floor of the Jiangsu Environmental Monitoring Center building ( $\sim 18 \mathrm{~m}$ above the ground), which is located in the urban area and surrounded by a variety of sources such as residence, restaurants, office blocks, and traffic.

\section{NUIST site}

Wu et al. (2014) measured aerosol hygroscopic growth as a function of RH $(60 \%-90 \%)$ at the NUIST site in MayJuly 2012, and bimodal hygroscopicity distributions were frequently observed at $90 \% \mathrm{RH}$ for $40-200 \mathrm{~nm}$ aerosols. For the more hygroscopic mode, average $\kappa$ values were determined to be $0.294-0.349$, increasing with particle size (except for $40 \mathrm{~nm}$ ), while for the less hygroscopic mode, average $\kappa$ values were found to decrease with particle size from 0.079 at $40 \mathrm{~nm}$ to 0.040 at $200 \mathrm{~nm}$ (Wu et al., 2014). The average aerosol hygroscopicity measured at this site in Nanjing seemed to be slightly lower than those reported in Beijing, Shanghai, and Guangzhou.

Yang and colleagues further investigated aerosol (30$230 \mathrm{~nm}$ ) hygroscopic growth (at $90 \% \mathrm{RH}$ ) at this site in April-May 2014 (Xu et al., 2015; Yang et al., 2019), and a bimodal hygroscopicity distribution was observed. The average $\kappa$ values were found to be very low (close to 0 ) for the low hygroscopic mode and decreased from 0.232 at $30 \mathrm{~nm}$ to 0.186 at $230 \mathrm{~nm}$ for the medium hygroscopic mode. Aerosol hygroscopicity measured in April-May 2014 (Xu et al., 2015; Yang et al., 2019) was significantly lower than that measured in May-June 2012 at the same site (Wu et al., 2014). One possible reason for the difference in aerosol hygroscopicity observed in the two periods at the same site was that in April-May 2014, organic species made a large contribution to submicrometer aerosols $(21 \%-38 \%$ by mass) (Xu et al., 2015; Yang et al., 2019), thus leading to a substantial decrease in aerosol hygroscopicity.

\section{NATC site}

In August 2013, Q. Li et al. (2015) investigated hygroscopic growth at $90 \% \mathrm{RH}$ for $32-350 \mathrm{~nm}$ aerosols. A less hydrophobic mode $(\kappa: 0.017-0.031)$ and a more hygroscopic mode $(\kappa$ : $0.178-0.229$ ) were observed during the campaign (Q. Li et al., 2015). Aerosol hygroscopicity reported at the NATC site in August 2013 (Q. Li et al., 2015) was lower than these reported at the NUIST site in May-June 2012 (Wu et al., 2014) and in April-May 2014 (Xu et al., 2015; Yang et al., 2019) perhaps because the contribution of low hygroscopic primary particles (e.g., soot) from local emissions was larger at the NATC site (an urban site) compared to the NUIST site (a suburban site).

\section{JEMC site}

At the JEMC site, 40-200 $\mathrm{nm}$ aerosol hygroscopic growth was measured at $85 \%$ RH in January-February 2015 (Zhang et al., 2018). The average $\kappa$ values were determined to be 0.200-0.271 for 40-200 nm particles (Zhang et al., 2018), significantly larger than those $(0.081-0.126$ for $32-350 \mathrm{~nm}$ particles) reported at the NATC site in August 2013 (Q. Li et al., 2015), and the reason was unclear. Bimodal hygroscopicity distribution was also observed (Zhang et al., 2018); similar to two previous studies in Nanjing (Wu et al., 2014; Q. Li et al., 2015), number fractions of particles in the low hygroscopic mode and their average $\kappa$ values both decreased with particle size, while the average $\kappa$ values increased with particle size for the more hygroscopic mode (except for $40 \mathrm{~nm}$ ).

\subsection{Pearl River Delta}

A series of aerosol hygroscopic growth studies were conducted in PRD, to be more specific, at two rural sites (Xinken and Wanqinsha), one suburban site (Panyu) in Guangzhou, and one suburban site (HKUST) in Hong Kong.

\subsubsection{Rural sites in Guangzhou}

The Xinken site $\left(22.6^{\circ} \mathrm{N}, 113.6^{\circ} \mathrm{E}\right)$, located near the Pearl River estuary, is $\sim 50 \mathrm{~km}$ southeast of urban Guangzhou, and the Wanqinsha site is located $\sim 9 \mathrm{~km}$ northwest of Xinken. Both are typical rural background sites with no major pollution sources nearby, and air quality at both sites is affected by regional transport combined with limited local sources, such as traffic, ships, biomass burning, and cooking (Cheng et al., 2006; Eichler et al., 2008; Kim et al., 2011).

Eichler et al. (2008) measured aerosol hygroscopic growth (30\%-91\% RH) at the Xinken site in October-November 2004. The average GFs at $91 \%$ RH were determined to 1.45 , $1.53,1.6$, and 1.56 for $80,140,250$, and $380 \mathrm{~nm}$ particles (Eichler et al., 2008), corresponding to $\kappa$ values of 0.244 , $0.283,0.324$, and 0.288 , respectively. Inorganic aerosol compositions measured offline were used to calculate GF, and the average difference between the measured and calculated GF was found to be $<8 \%$ (Eichler et al., 2008), suggesting that the contribution of organics to aerosol hygroscopicity was rather small.

In a following study (Kim et al., 2011), aerosol hygroscopic growth (at $85 \% \mathrm{RH}$ ) of ultrafine particles (40, 50,60 , and $80 \mathrm{~nm}$ ) was investigated at the Wanqinsha site in October-November 2008. During photochemical events, GF varied between 1.13 and 1.55, and particles consisted mainly of ammonium sulfate and organic materials (Kim et al., 2011). For comparison, during combustion events (i.e., affected by biomass burning and traffic emissions), aerosol particles were mainly composed of non-hygroscopic carbonaceous species and smaller amounts of potassium, and 
correspondingly measured GFs were reduced to $1.05-1.15$ (Kim et al., 2011).

\subsubsection{Urban and suburban sites in Guangzhou}

The Panyu site, located at the top of Mt. Dazhengang $\left(23^{\circ} 00^{\prime} \mathrm{N}, 113^{\circ} 21^{\prime} \mathrm{E}, 150 \mathrm{~m}\right.$ above sea level), is surrounded by residential areas without major pollution sources nearby and can be considered as a suburban site in Guangzhou (Tan et al., 2013). Several aerosol hygroscopic growth measurements at $90 \% \mathrm{RH}$ have been carried out at this site since 2011 (Tan et al., 2013; Jiang et al., 2016; Cai et al., 2017; Tan et al., 2017; Cai et al., 2018; Hong et al., 2018; L. Liu et al., 2018).

Aerosol hygroscopic growth was first measured at this site in November-December 2011 (Tan et al., 2013). Bimodal hygroscopicity distributions were observed for 40, 80, 110, 150 , and $200 \mathrm{~nm}$ particles, and $\kappa$ values were determined to be $0.045-0.091$ and $0.290-0.323$ for the less and more hygroscopic modes (Tan et al., 2013). In general, both hygroscopicity and number fractions increased with particle size for the more hygroscopic mode, whereas they both decreased with particle size for the less hygroscopic mode. Average hygroscopicity was found to be larger during the daytime than the nighttime for both modes due to strong photochemical aging in the daytime (Tan et al., 2013), and hygroscopicity and number fractions of particles in the more hygroscopic mode increased during polluted periods when compared to clean periods.

Jiang et al. (2016) compared aerosol hygroscopicity measured at this site between winter (December 2012-January 2013) and summer (July-September 2013), and no obvious difference in average $\kappa$ values was found between the two seasons. Trimodal hygroscopicity distributions were observed for $40-200 \mathrm{~nm}$ particles, and $\kappa$ values were determined to be $0.290-0.339, \sim 0.15$, and $\sim 0.015$ for more, less, and non-hygroscopic modes (Jiang et al., 2016). Similar to the work by Tan et al. (2013), hygroscopicity and number fractions increased with particle size for the more hygroscopic mode with no distinct difference between winter and summer (Jiang et al., 2016); for the non-hygroscopic mode, hygroscopicity and number fractions both decreased with particle size, and their number fractions were slightly lower in winter than in summer. The average $\kappa$ values were larger during daytime than nighttime for both seasons due to stronger atmospheric aging in the daytime; furthermore, the diurnal variation of aerosol hygroscopicity was more profound in summer, as daytime photochemical aging in the summer was more intensive than winter (Jiang et al., 2016).

Tan et al. (2017) measured aerosol hygroscopic growth in January-March 2014, and average $\kappa$ values increased from 0.204 at $40 \mathrm{~nm}$ to 0.312 at $200 \mathrm{~nm}$. The $\kappa$ values derived from GF measured at $90 \%$ RH were used to calculate ALWC under ambient conditions, and at the same time, aerosol inorganic species measured were used as input in ISORROPIA-
II to predict ALWC. Good agreement between calculated and predicted ALWC were found for RH $>70 \%$, but significant differences were found at $<70 \% \mathrm{RH}$ (Tan et al., 2017). L. Liu et al. (2018) further explored aerosol hygroscopic growth measured in February-March 2014 at this site and found that the average $\kappa$ values increased from 0.261 at $80 \mathrm{~nm}$ to 0.323 at $200 \mathrm{~nm}$. In addition, bimodal hygroscopicity distribution was observed, and average $\kappa$ values increased from 0.382 at $80 \mathrm{~nm}$ to 0.432 at $200 \mathrm{~nm}$ for the more hygroscopic mode (L. Liu et al., 2018).

Aerosol hygroscopic growth (at $90 \% \mathrm{RH}$ ) was further measured at this site in November-December 2014 (Cai et al., 2017, 2018). Bimodal hygroscopicity distributions were observed for $40-200 \mathrm{~nm}$ particles, and the average $\kappa$ values increased with particle size from 0.213 at $40 \mathrm{~nm}$ to 0.312 at $200 \mathrm{~nm}$. The $\kappa$ values derived from size-resolved chemical compositions measured using AMS were significantly lower than those derived from GF measurements (Cai et al., 2017, 2018) probably because using a constant $\kappa$ value $(0.1)$ may underestimate hygroscopicity of aerosol organics or mixed inorganic and organic aerosols.

Aerosol composition and hygroscopic growth at $90 \% \mathrm{RH}$ were investigated at this site in September-October 2016 (Hong et al., 2018) using an ACSM and a H-TDMA. Bimodal hygroscopicity distributions were observed; the more hygroscopic mode was dominant at 100 and $145 \mathrm{~nm}$, while less and more hygroscopic modes were of similar magnitudes at 30 and $60 \mathrm{~nm}$ (Hong et al., 2018). The average aerosol hygroscopicity increased with particle size, and no obvious diurnal variation was observed (Hong et al., 2018); however, aerosol hygroscopicity was higher during the daytime for the less hygroscopic mode while slightly lower in the afternoon for the more hygroscopic mode. Hygroscopicity closure analysis suggested that taking into account the dependence of GF on composition for organics led to better agreement between measured and calculated GFs (Hong et al., 2018). A linear relationship was found between GF and $\mathrm{O}: \mathrm{C}$ ratios for aerosol organics, and the derived GF appeared to be less sensitive to the changes in $\mathrm{O}: \mathrm{C}$ ratios during polluted periods.

\subsubsection{Hong Kong}

Since 2011, H-TDMA and online mass spectrometry were employed by Chan and colleagues (Lopez-Yglesias et al., 2014; Yeung et al., 2014; Cheung et al., 2015) to investigate aerosol composition and hygroscopic growth at the HKUST supersite $\left(22^{\circ} 20^{\prime} \mathrm{N}, 114^{\circ} 16^{\prime} \mathrm{E}\right)$ on the east coast of Hong Kong. It is a typical suburban and coastal site with no major pollution sources nearby.

Aerosol hygroscopic growth at $90 \% \mathrm{RH}$ was first investigated at this site in 2011 (Yeung et al., 2014), and bimodal aerosol hygroscopicity distributions were observed with a dominant more hygroscopic mode and a weak less hygroscopic mode at 75, 100, 150, and $200 \mathrm{~nm}$. The average $\kappa$ values were determined to be $0.330-0.360$ during May, 0.370- 
0.390 during the first half of September, $0.210-0.250$ during the second half of September, and 0.290-0.320 during November (Yeung et al., 2014), which were caused by compositional variations in different air masses. Since aerosol particles arriving at this site were heavily aged and internally mixed well, no obvious dependence of average $\kappa$ values on particle size was found.

Number fractions of particles in the more hygroscopic mode were always $>0.8$ (Yeung et al., 2014) except for $75 \mathrm{~nm}$ particles in the second half of September $(\sim 0.45)$ which was dominantly affected by continental air masses. When compared to maritime aerosols, the hygroscopicity of aerosols in the more hygroscopic mode was substantially lower for continental aerosols which contained larger proportions of organic matter (Yeung et al., 2014). Hygroscopicity closure analysis suggested that using a constant GF (1.18) at $90 \% \mathrm{RH}$ for organic materials instead of considering the dependence of GF on their oxidation degree would lead to better agreement between measured and calculated GFs (Yeung et al., 2014) likely because inorganic species (such as sulfate) contributed dominantly to the overall aerosol hygroscopicity during the entire campaign.

In addition, hygroscopic growth at the HKUST site was investigated as a function of RH (10\%-90\%) in 2011-2012 (Lopez-Yglesias et al., 2014; Cheung et al., 2015), and both hysteresis behavior and continuous hygroscopic growth of ambient aerosols were observed.

\subsection{Other locations}

In addition to NCP, YRD, and PRD, measurements of aerosol hygroscopic growth were also conducted in other regions in China, as discussed below.

\subsubsection{Taipei}

Hygroscopic growth (15\%-90\% RH) was investigated for 53, 82, 95, and $202 \mathrm{~nm}$ aerosols at an urban site in Taipei (Taiwan Province) in October-December 2001 (Chen et al., 2003). Bimodal hygroscopicity distribution was observed for all the particles at $90 \% \mathrm{RH}$, while $\kappa$ values $(0.049-0.068)$ showed no obvious dependence on particle size for the less hygroscopic mode, they increased from 0.274 at $53 \mathrm{~nm}$ to 0.422 at $202 \mathrm{~nm}$ for the more hygroscopic mode (Chen et al., 2003). No obvious hygroscopic growth was observed at $<45 \%$ RH (Chen et al., 2003), and bimodal hygroscopic growth behavior appeared at $\sim 76 \%$ RH for all the sizes (53$202 \mathrm{~nm}$ ), becoming more noticeable with a further increase in $\mathrm{RH}$.

\subsubsection{Mt. Huang}

Mt. Huang $\left(30^{\circ} 08^{\prime} \mathrm{N}, 118^{\circ} 09^{\prime} \mathrm{E}\right)$ is located in the mountainous area of eastern China with large forest coverage and limited anthropogenic activities. Aerosol hygroscopic growth at $50 \%-85 \%$ RH was examined in September-October 2012 at the mountain's foot ( $\sim 464 \mathrm{~m}$ above sea level) and the mountain top ( $\sim 1860 \mathrm{~m}$ above sea level) (Y. Wu et al., 2018). No significant particle growth was observed below $60 \% \mathrm{RH}$ at both sites, and bimodal growth behavior appeared at $\sim 75 \%$ RH except for $40 \mathrm{~nm}$ particles and became more evident at higher RH (80\% and 85\%) (Y. Wu et al., 2018). Hygroscopicity was higher in the daytime than the nighttime for both modes. In addition, hygroscopicity was slightly higher at the mountain's foot than the mountain top for both modes (except $200 \mathrm{~nm}$ particles in the more hygroscopic mode) (Y. Wu et al., 2018); the reason was that more secondary inorganic species were formed at the mountain's foot due to human activities, while on the mountain top the contribution of organics increased. Compared to the NCP, YRD, and PRD sites, the overall aerosol hygroscopicity was lower at Mt. Huang (Y. Wu et al., 2018) as it is located in a clean region with smaller fractions of secondary inorganic aerosols.

In July 2014, aerosol hygroscopic growth (at $85 \% \mathrm{RH}$ ) was further studied at the top of Mt. Huang (Xu, 2015; Chen et al., 2016; Wang et al., 2016). The average $\kappa$ values were determined to be $0.275,0.266$, and 0.290 at 70 , 150, and $230 \mathrm{~nm}$ (Chen et al., 2016; Wang et al., 2016), which are in good agreement with the previous study conducted at the same site in 2012 (Y. Wu et al., 2018). At a given particle size, aerosol hygroscopicity was found to be higher in the daytime than the nighttime (Chen et al., 2016; Wang et al., 2016); furthermore, aerosol hygroscopicity was higher for air masses from the northwest than that from the southeast. The derived $\kappa$ values depended positively on mass fractions of inorganics and negatively on organics (Chen et al., 2016; Wang et al., 2016). In addition, unimodal aerosol hygroscopicity distribution occurred with high frequency (47.5\%) during the campaign, and it also appeared more frequently in the afternoon with GF (at $85 \% \mathrm{RH}$ ) in the range of 1.25-1.45 (Chen et al., 2016; Wang et al., 2016).

\subsubsection{Shouxian}

In June-July 2016, Qian et al. (2017) studied hygroscopic growth (at $90 \% \mathrm{RH})$ of $50-250 \mathrm{~nm}$ aerosols at Shouxian National Climate Observatory $\left(32^{\circ} 26^{\prime} \mathrm{N}, 116^{\circ} 48^{\prime} \mathrm{E}\right)$ in eastern China, a rural site surrounded by farmland in Shouxian, Anhui Province. Bimodal aerosol hygroscopicity distribution was observed, and the average $\kappa$ values increased with particle size from 0.129 at $50 \mathrm{~nm}$ to 0.279 at $250 \mathrm{~nm}$ (Qian et al., 2017).

\subsubsection{East China Sea}

Total suspended particles were collected during a cruise over the East China Sea $\left(22-35^{\circ} \mathrm{N}\right.$ and $\left.119-126^{\circ} \mathrm{E}\right)$ in May-June 2014 and dissolved in deionized water. The resulting solutions were atomized to generate aerosols, and their hygroscopic growth was then measured at 5\%-90\% RH (Yan et al., 2017). The average $\kappa$ value was determined to be 0.88 for 
the whole cruise, and the daytime average (0.81) was smaller than the nighttime average (0.95) (Yan et al., 2017) due to less chloride loss in the nighttime. It has yet to be assessed to what extent aerosols generated by Yan et al. (2017) can actually mimic ambient aerosols.

\subsection{Summary}

Geographically speaking, almost all of the aerosol hygroscopic growth studies were conducted in eastern China, especially in NCP, YRD, and PRD. Aerosol hygroscopic growth in other regions in China remains to be explored, and measurements at rural and remote areas with limited anthropogenic impacts are very scarce. In addition, previous measurements were mainly performed at or close to ground level, except these carried out on the top of Mt. Huang (Chen et al., 2016; Wang et al., 2016; Y. Wu et al., 2018).

It can be concluded that submicrometer aerosols in China usually exhibit a bimodal hygroscopicity distribution (i.e., nearly hydrophobic and more hygroscopic modes). Trimodal distributions, with a medium hygroscopic mode with limited importance, were also reported by several studies (Massling et al., 2009; Meier et al., 2009; Ye et al., 2013; Jiang et al., 2016; S. L. Zhang et al., 2016; Y. Wang et al., 2017b; $\mathrm{X}$. Wang et al., 2018). Bimodal or trimodal hygroscopicity distributions suggested that aerosol particles under investigation were externally mixed. Quasi-unimodal hygroscopicity distributions existed but were quite sparse (Chen et al., 2016; Wang et al., 2016; Y. Wang et al., 2017b; Zhang et al., 2017; Y. Wang et al., 2018a), implying that these aerosols were nearly internally mixed.

For the more hygroscopic mode, $\kappa$ values usually increased with particle size except for the measurements carried out at the HKUST site (Yeung et al., 2014) where no obvious dependence on particle diameter was found. For the nearly hydrophobic mode, $\kappa$ values usually decreased with particle size (Liu et al., 2011; Ye et al., 2011; Zhang et al., 2011; Tan et al., 2013; Ye et al., 2013; Wu et al., 2014; Jiang et al., 2016; S. L. Zhang et al., 2016; Qian et al., 2017; Zhang et al., 2018), though opposite results were also reported in several studies (Chen et al., 2003; Massling et al., 2009; Meier et al., 2009; Q. Li et al., 2015; X. Wang et al., 2018; Y. Wu et al., 2018).

Average aerosol hygroscopicity, especially for the more hygroscopic mode, usually increased with pollution levels (Massling et al., 2009; Wu et al., 2016; Y. Wang et al., 2017b; X. Wang et al., 2018; Chen et al., 2019; Ding et al., 2019; Y. Wang et al., 2019), which is attributed to increased mass fractions of secondary inorganic aerosols. However, different results were also reported, especially for particles at or below $50 \mathrm{~nm}$ (Achtert et al., 2009; Meier et al., 2009; X. Wang et al., 2018; Y. Wang et al., 2019) for which primary emissions could play an important role.

A few studies examined aerosol hygroscopic growth at different seasons (Massling et al., 2009; Jiang et al., 2016;
Y. Wang et al., 2018b; Fan et al., 2020). No obvious difference in the overall aerosol hygroscopicity was observed between summer and winter at the PKU site (Beijing) (Massling et al., 2009), the IAP site (Beijing) (Fan et al., 2020), or the Panyu site (Guangzhou) (Jiang et al., 2016). However, one study (Y. Wang et al., 2018b) suggested that the overall hygroscopicity, and especially the hygroscopicity of 150-350 particles, was highest in summer and lowest in winter at the PKU site (Beijing); one possible reason was that aerosol particles examined by Y. Wang et al. (2018b) were most aged in the summer (and thus contained the largest fractions of secondary species with high hygroscopicity) and least aged in the winter.

Diurnal variations of aerosol hygroscopic growth were also investigated. Most of these studies suggested that aerosol hygroscopicity was generally higher in the daytime compared to the nighttime. For example, hygroscopicity was higher in the daytime than the nighttime for the Aitken mode at the Yufa site (Beijing) in August-September 2006 (Achtert et al., 2009), while no significant difference was found between daytime and nighttime for the accumulation mode. In addition, aerosol hygroscopicity was found to be higher in the daytime than the nighttime at the IAP site (Beijing) in August-October 2015 (Y. Wang et al., 2017b), at the Wuqing site (Tianjin) in July-August 2009 for the more hygroscopic mode (Liu et al., 2011), at the Xingtai site (Hebei) in May-June 2016 (Y. Wang et al., 2018a), at the Panyu site (Guangzhou) in NovemberDecember 2011 (Tan et al., 2013), December 2012-January 2013 (Jiang et al., 2016), and July-September 2013 (Jiang et al., 2016), and at Mt. Huang in September-October 2012 (Y. Wu et al., 2018) and July 2014 (Chen et al., 2016; Wang et al., 2016). The underlying reason was that photochemical processes during the daytime led to an increased relative contribution of secondary aerosols which were very hygroscopic. However, there are also exceptions. For example, $\kappa$ was larger in the nighttime than the daytime for the accumulation mode at the NKU site (Tianjin) in March 2017 (Ding et al., 2019) as high RH in the nighttime may enhance sulfate and nitrate formation from the aqueous oxidation of $\mathrm{SO}_{2}$ and heterogeneous hydrolysis of $\mathrm{N}_{2} \mathrm{O}_{5}$ (H. Wang et al., 2017). In addition, no obvious diurnal variation in average aerosol hygroscopicity was observed at the Panyu site (Guangzhou) in September-October 2016 (Hong et al., 2018), though aerosol hygroscopicity was higher during the daytime for the less hygroscopic mode and slightly lower in the afternoon for the more hygroscopic mode.

While aerosol hygroscopic growth measurements were typically carried out at a single $\mathrm{RH}$ at around $90 \%$, several studies also investigated aerosol hygroscopic growth at different RHs (Chen et al., 2003; Eichler et al., 2008; Achtert et al., 2009; Meier et al., 2009; Liu et al., 2011; Ye et al., 2011; Zhang et al., 2011; Cheung et al., 2015; X. Wang et al., 2018; Y. Wu et al., 2018). As shown in Fig. 5, for the measurement carried out at the ZJU site (Hangzhou) in December 2009- 


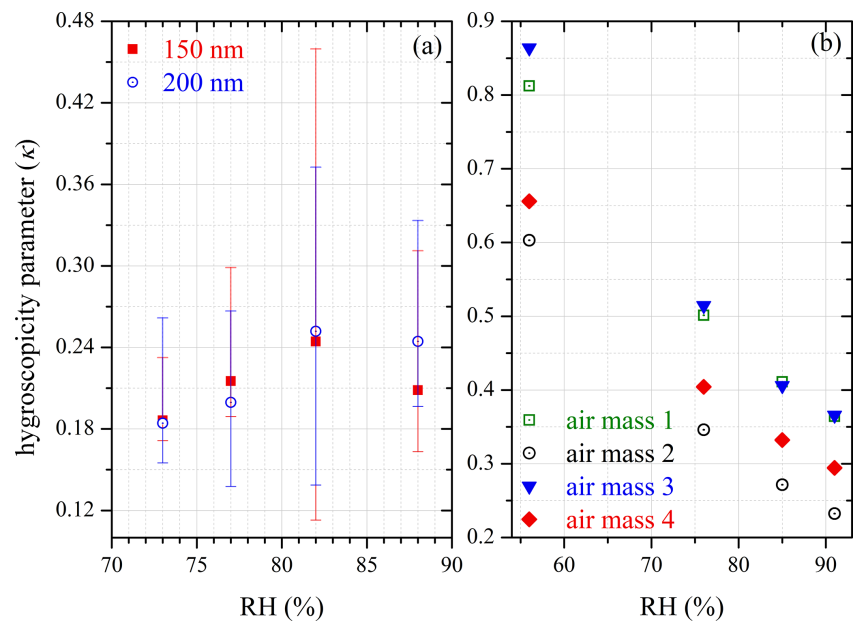

Figure 5. Single hygroscopicity parameters $(\kappa)$ derived from GF measured at different RHs. (a) 150 and $200 \mathrm{~nm}$ particles at the ZJU site (Hangzhou) in December 2009-January 2010 (Zhang et al., 2011); (b) $250 \mathrm{~nm}$ particles at the Yufa site (Beijing) in AugustSeptember 2006 for four typical air masses (Achtert et al., 2009). Error bars are not shown in (b) as uncertainties are not provided in the original paper.

January 2010 (Zhang et al., 2011), average $\kappa$ values derived from measured GF at different RHs $(73 \%-88 \%)$ varied from 0.186 to 0.244 for $150 \mathrm{~nm}$ particles and from 0.184 to 0.252 for $200 \mathrm{~nm}$ particles. For the measurement carried out at the Yufa site (Beijing) in August-September 2006 (Achtert et al., 2009), average $\kappa$ values were found to decrease with increasing $\mathrm{RH}(56 \%-91 \%)$ for $250 \mathrm{~nm}$ particles, varying from $\sim 0.3$ to $\sim 0.8$. Considerable variations of $\kappa$ with $\mathrm{RH}$ were also reported in other studies (Chen et al., 2003; Meier et al., 2009; Ye et al., 2011; Cheung et al., 2015). Therefore, it can be concluded that using a constant $\kappa$ to describe aerosol hygroscopic growth at different RHs may not always be proper. In addition, during most H-TDMA measurements, aerosols were first dried at low RH (typically $<15 \%$ ) and then humidified to a given $\mathrm{RH}$, and as a result these measurements could not simulate the formation of supersaturated droplets which may exist even when RH was below the corresponding deliquescence RH but above the efflorescence RH.

\section{CCN activities}

As stated in Sect. 2.2, we only discuss CCN activity measurements which reported $\kappa$ values herein. Section 4.1-4.3 review measurements conducted in NCP, YRD, and PRD, and measurements carried out in other regions in China are discussed in Sect. 4.4.

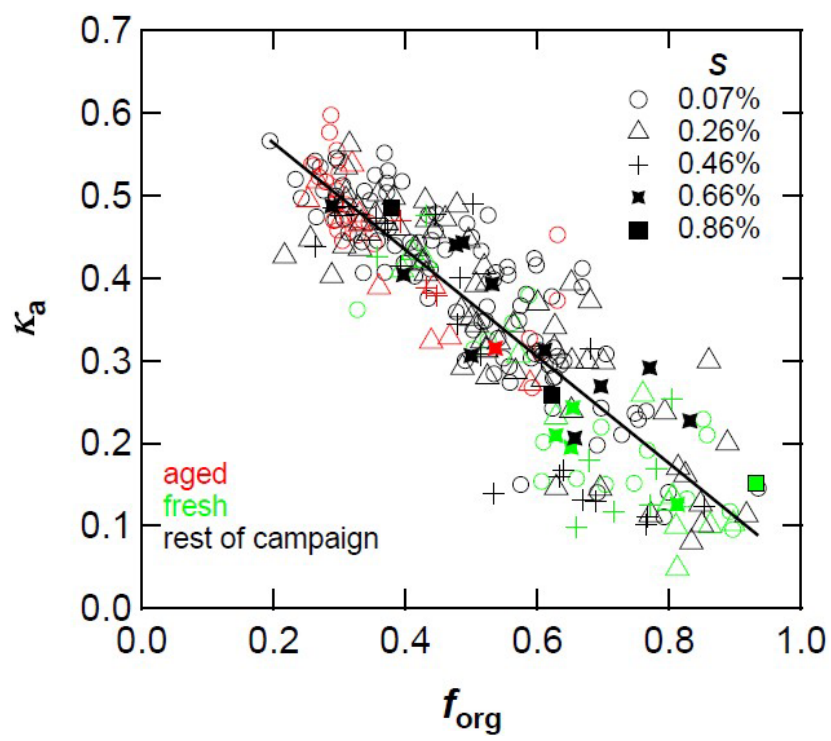

Figure 6. Dependence of $\kappa_{\mathrm{a}}$ on mass fractions of organics for three periods over the campaign (red: the aged regional pollution period; green: the fresh city pollution period; black: the rest of the campaign). Reprint with permission by Gunthe et al. (2011).

\subsection{North China Plain}

\subsubsection{Beijing}

In August-September 2006, size-resolved CCN activities were measured at the Yufa site (Gunthe et al., 2011). Maximum activation fractions were around 1 for supersaturation in the range of $0.26 \%-0.86 \%$; however, they only reached $\sim 0.8$ on average at $0.07 \%$ supersaturation, and these inactive particles were mainly soot. For the entire measurement period, the average $\kappa_{\mathrm{a}}$ and $\kappa_{\mathrm{t}}$ were both determined to be $0.3 \pm 0.1$. CCN activities were found to increase with particle size due to increased mass fractions of soluble inorganics (Gunthe et al., 2011), and $\kappa_{\mathrm{a}}$ values were measured to be $\sim 0.2$ at $\sim 40 \mathrm{~nm}$ and $\sim 0.5$ at $200 \mathrm{~nm}$. During periods affected by aged regional pollution, mass fractions of soluble inorganics were enhanced, leading to an increase in $\kappa_{\mathrm{a}}$ (0.35 \pm 0.05$)$ (Gunthe et al., 2011); in contrast, mass fractions of organics increased during periods influenced by fresh city pollution, resulting in a decrease in $\kappa_{\mathrm{a}}(0.22 \pm 0.07)$.

As shown in Fig. 6, the measured $\mathrm{CCN}$ activities decreased as mass fractions of organics increased (Gunthe et al., 2011); furthermore, the measured $\kappa_{\mathrm{a}}$ could be quantitatively described by mass fractions of soluble inorganics and organics, and their $\kappa$ values were determined to be 0.7 and 0.1 . Aerosol $\mathrm{CCN}$ activities during a rapid particle growth event on $23 \mathrm{Au}-$ gust were further examined (Wiedensohler et al., 2009), during which CCN size distribution was dominated by the growing nucleation mode instead of the accumulation mode as usual. 


\section{2}

Measurements were carried out at the PKU site to investigate size-resolved CCN activities in May-June 2014 (Wu et al., 2017). Similar to the concurrent H-TDMA measurements, average $\kappa_{\mathrm{a}}$ was determined to be $\sim 0.10$ during biomass burning events, displaying no dependence on particle size (Wu et al., 2017). CCN activities of submicrometer particles were significantly reduced during biomass burning periods due to increased mass fractions of organics and black carbon. Furthermore, average $\kappa$ values calculated from aerosol compositions measured using AMS were consistent with those derived from hygroscopic growth and $\mathrm{CCN}$ activity measurements (Wu et al., 2017) if $\kappa$ values were assumed to be 0.53 for inorganics and 0 for organics, respectively.

Zhang et al. (2017) investigated size-resolved CCN activities at the IAP site in November-December 2014 and August-September 2015, and maximum activation fractions were found to be much smaller than 1 , indicating large fractions of $\mathrm{CCN}$-inactive particles from local primary emissions. The average $\kappa_{\mathrm{a}}$ values, which ranged from 0.22 to 0.31 for $60-150 \mathrm{~nm}$ particles and increased with particle size (Zhang et al., 2017), agreed well with those derived from the concurrent H-TDMA measurements (Y. Wang et al., 2017b). In addition, $\kappa$ values $(0.32 \pm 0.11)$ calculated using ACSMmeasured aerosol composition were significantly larger than those derived from hygroscopic growth $(0.25 \pm 0.08)$ and CCN activities $(0.26 \pm 0.04)$ (Zhang et al., 2017). This was because hygroscopicity estimated using ACSM-measured composition did not consider the contribution of smaller and less hygroscopic particles (aerosol hygroscopicity was lower for smaller particles, but ACSM only detected $>60 \mathrm{~nm}$ particles). In addition, the uncertainties associated with $\kappa$ values assumed for ammonium sulfate, ammonium nitrates, and organics may also contribute to the discrepancies between measurement and calculation.

In November-December 2016, F. Zhang et al. (2019) further investigated size-resolved CCN activities at the IAP site and found that $[\mathrm{CCN}]$ was significantly increased during nucleation-initiated haze episodes. It was suggested that increase in particle size contributed $>80 \%$ to the observed increase in [CCN] (Ren et al., 2018; F. Zhang et al., 2019), while the effect of aerosol hygroscopicity enhancement due to change in aerosol composition was much smaller.

\subsubsection{Other locations in NCP}

Zhang et al. (2014, 2017) measured size-resolved CCN activities at the Xianghe site $\left(39.75^{\circ} \mathrm{N}, 116.96^{\circ} \mathrm{E}\right)$ in JuneJuly 2013. Average $\kappa_{\mathrm{a}}$ values were determined to be 0.24 0.32 during polluted periods, showing no dependence on particle size; in contrast, $\kappa_{\mathrm{a}}$ values increased from $\sim 0.22$ at $\sim 50 \mathrm{~nm}$ to $\sim 0.38$ at $\sim 180 \mathrm{~nm}$ for background days (Zhang et al., 2014). Compared to polluted periods, $\kappa_{\mathrm{a}}$ values were $\sim 20 \%$ larger under background conditions for the accumulation mode (100-200 nm) as the contribution of aerosol organics from fresh biomass burning was significantly in- creased during pollution events (Zhang et al., 2014); however, $\kappa_{\mathrm{a}}$ values were very similar for the nucleation/Aitken modes $(40-100 \mathrm{~nm})$ under background and polluted conditions.

Size-resolved CCN activities were further investigated at the Xianghe site in July-August 2013 (Ma et al., 2016; Tao et al., 2020), and it was found that $\kappa_{\mathrm{a}}$ values increased with particle size from $0.22 \pm 0.02$ at $46 \mathrm{~nm}$ to $0.38 \pm 0.02$ at $179 \mathrm{~nm}$. Compared to $\kappa$ values (increasing from $0.291 \pm 0.089$ at $50 \mathrm{~nm}$ to $0.373 \pm 0.092$ at $350 \mathrm{~nm}$ ) derived from concurrent H-TDMA measurements, aerosol hygroscopicity derived from CCN activities were slightly lower for $<50 \mathrm{~nm}$ particles but higher for $>100 \mathrm{~nm}$ particles (Ma et al., 2016; S. L. Zhang et al., 2016), but the differences were quite small.

F. Zhang et al. (2016), Zhang et al. (2017), and Y. Li et al. (2017) also investigated size-resolved CCN activities at the Xinzhou site in July-August 2014. The average $\kappa_{\mathrm{a}}$ values were determined to be $0.42-0.51$ for $37-150 \mathrm{~nm}$ particles, exhibiting no dependence on particle size (Zhang et al., 2017); in addition, compared to other sites in the NCP, aerosols at the Xinzhou site displayed significantly higher $\mathrm{CCN}$ activities. This is because aerosols observed at this site were highly aged and internally mixed well after undergoing regional transport for a long time, and thus the variation of chemical compositions with particle size was negligible. The average $\kappa_{\mathrm{a}}$ values $(0.48 \pm 0.07)$ (Zhang et al., 2017) agreed well with that $(0.47 \pm 0.03)$ determined from concurrent H-TDMA measurements (Zhang et al., 2017), both of which are significantly larger than that $(0.41 \pm 0.06)$ calculated from ACSM-measured aerosol composition probably because such calculation may underestimate the hygroscopicity of aerosol organics.

\subsection{Yangtze River Delta}

Size-resolved CCN activity measurements were conducted in August 2013 at the observation station of the Nanjing Bureau of Meteorology $\left(32.04^{\circ} \mathrm{N}, 118.70^{\circ} \mathrm{E}\right)$ on Jiangxi Island in the Yangtze River (Ma et al., 2017). This site, located in a suburban area of Nanjing, did not have significant local emissions at that time. The $\kappa_{\mathrm{a}}$ values were found to range from $\sim 0.1$ to $\sim 0.8$ during the campaign, being $0.35 \pm 0.13$ on average (Ma et al., 2017), and no significant variation in average $\kappa_{\mathrm{a}}$ values was found for biomass burning, urban, marine, and industrial air masses. In addition, $\kappa_{\mathrm{a}}$ values increased from $0.30 \pm 0.08$ at $\sim 55 \mathrm{~nm}$ to $0.34 \pm 0.08$ at $67 \mathrm{~nm}$ due to the larger contribution of low hygroscopic organics at $50 \mathrm{~nm}$; however, a further increase in particle size up to $\sim 149 \mathrm{~nm}$ did not lead to an obvious increase in $\kappa_{\mathrm{a}}$ values (Ma et al., 2017) likely because aerosols arriving at this site were heavily aged and internally mixed well.

Long-term size-resolved CCN activities were studied in January-December 2013 at the Lin' an site (Hangzhou, Zhejiang Province) (Che et al., 2016, 2017), which is a World Meteorological Organization (WMO) Global Atmospheric 
Watch regional station $\left(30.3^{\circ} \mathrm{N}, 119.73^{\circ} \mathrm{E}, 138 \mathrm{~m}\right.$ above sea level) located in the center of YRD. Maximum activation fractions were close to 1 at high supersaturation but only reached $\sim 0.89$ at $0.1 \%$ supersaturation. Values of $\kappa_{\mathrm{a}}$ and $\kappa_{\mathrm{t}}$ were almost identical $(\sim 0.25)$ at $40-50 \mathrm{~nm}$ and increased to $\sim 0.42\left(\kappa_{\mathrm{a}}\right)$ and $\sim 0.40\left(\kappa_{\mathrm{t}}\right)$ at $100-150 \mathrm{~nm}$ (Che et al., 2017), suggesting that larger particles contained larger fractions of hygroscopic species (e.g., soluble inorganics). Furthermore, CCN activities were also compared under nine different weather-pollution conditions (Che et al., 2016), and $\kappa$ values were determined to be $\sim 0.7$ and $\sim 0.1$ for inorganics and organics during haze episodes and $\sim 0.6$ and $\sim 0.2$ for other episodes.

\subsection{Pearl River Delta}

Rose et al. (2010, 2011) explored size-resolved CCN activities in July 2006 at the Backgarden site, which is a suburban site $\left(23.55^{\circ} \mathrm{N}, 113.07^{\circ} \mathrm{E}\right)$ located $\sim 60 \mathrm{~km}$ northwest of Guangzhou. Maximum activation fractions were close to 1 at medium and high supersaturations $(0.47 \%-1.27 \%)$ and well below 1 at low supersaturation $(0.068-0.27 \%$ ) (Rose et al., 2010), and particles not activated were mainly externally mixed soot with an estimated median $\kappa$ value of $\sim 0.01$ (Rose et al., 2011). The average $\kappa_{\mathrm{a}}$ and $\kappa_{\mathrm{t}}$ values were determined to be 0.34 and 0.30 over the entire campaign; to be more specific, $\kappa_{\mathrm{a}}$ and $\kappa_{\mathrm{t}}$ were almost identical $(\sim 0.3)$ for small particles and increased to $0.4-0.5$ and $\sim 0.33$ for large particles (Rose et al., 2010). The increase in average $\kappa_{\mathrm{a}}$ with diameter was mainly due to enhanced mass fractions of inorganics for larger particles (Rose et al., 2011). Compared to the rest of the campaign, $\kappa_{\mathrm{a}}$ and $\kappa_{\mathrm{t}}$ were reduced by $\sim 30 \%$ on average during biomass burning events $(0.34$ versus 0.24 ) when mass fractions of organics were substantially increased; moreover, the decrease in $\kappa_{\mathrm{t}}$ during biomass burning events was very substantial for $<100 \mathrm{~nm}$ particles but quite small for $\sim 200 \mathrm{~nm}$ particles (Rose et al., 2010). It was further found that assuming $\kappa$ values to be $\sim 0.6$ for inorganics and $\sim 0.1$ for organics could approximate the observed CCN activities over the entire campaign (Rose et al., 2011).

Size-resolved CCN activities were investigated at the Panyu site in November-December 2014 (Cai et al., 2018), and the average $\kappa_{\mathrm{a}}$ values were found to increase from 0.21 at $58 \mathrm{~nm}$ to 0.30 at $156 \mathrm{~nm}$ because mass fractions of organics, measured using AMS, decreased with particle size. The average $\kappa$ values derived from H-TDMA measurements agreed well with those derived from $\mathrm{CCN}$ measurements; however, they were larger than those calculated from sizeresolved chemical compositions, and the difference between measured and calculated $\kappa$ values increased with particle size (Cai et al., 2018). This discrepancy was probably because assuming a constant $\kappa$ value (0.1) may underestimate the hygroscopicity of aerosol organics.

Aerosol CCN properties were studied at the HKUST site in May 2011 (Meng et al., 2014), and maximum activation fractions were found to exceed 0.9 for the entire campaign, implying that the difference between $\kappa_{\mathrm{a}}$ and $\kappa_{\mathrm{t}}$ should be small. CCN activities were found to increase with particle size, with average $\kappa_{\mathrm{a}}$ being determined to be 0.28 at $46 \mathrm{~nm}$ to 0.39 at $116 \mathrm{~nm}$ (Meng et al., 2014) due to the increase in volume fractions of inorganics as revealed by AMS measurements. It was further found that the measured $\kappa_{\mathrm{a}}$ could be reasonably well predicted using volume fractions of inorganics and organics (Meng et al., 2014), and their $\kappa$ values were determined to be 0.6 and 0.1 .

\subsection{Other locations}

Hung et al. (2014, 2016) measured [CCN], [CN], and aerosol number size distribution in August 2011 at a rural site and in June 2012 at an urban site in Taiwan. The rural site $\left(25.89^{\circ} \mathrm{N}\right.$, $\left.121.57^{\circ} \mathrm{E}\right)$ is $\sim 15 \mathrm{~km}$ away from Taipei, while the urban site $\left(25.01^{\circ} \mathrm{N}, 121.54^{\circ} \mathrm{E}\right)$ is located on the campus of National Taiwan University in a metropolitan area of Taipei. At the rural site, $\kappa_{\text {cut }}$ values increased from $\sim 0.1$ at $\sim 50 \mathrm{~nm}$ to $\sim 0.35$ at $\sim 165 \mathrm{~nm}$ during the first period which was significantly affected by anthropogenic emissions, while they increased from $\sim 0.04$ at $\sim 70 \mathrm{~nm}$ to $\sim 0.28$ at $\sim 175 \mathrm{~nm}$ for the second period not significantly affected by anthropogenic emissions (Hung et al., 2014). Overall, $\kappa_{\text {cut }}$ was larger in the first period than the second period probably due to the impacts of aged air masses originating from cities nearby during the first period. Compared to the rural site, $\kappa_{\text {cut }}$ values were much smaller at the urban site, increasing from $\sim 0.021$ at $\sim 90 \mathrm{~nm}$ to 0.10 at $\sim 250 \mathrm{~nm}$ (Hung et al., 2016), indicating that fresh anthropogenic aerosols tended to exhibit lower hygroscopicity.

Shipborne size-resolved CCN activity measurements were carried out in September 2012 over remote regions of the South China Sea and East China Sea (Atwood et al., 2017). Under marine background conditions, the average $\kappa_{\mathrm{a}}$ values were determined to be $0.65 \pm 0.11$ and $0.46 \pm 0.17$ for the accumulation and Aitken modes (Atwood et al., 2017). Compared to marine background conditions, $\mathrm{CCN}$ activities were reduced after extensive precipitation, with average $\kappa_{\mathrm{a}}$ values determined to be $0.54 \pm 0.14$ and $0.34 \pm 0.11$ for the accumulation and Aitken modes, whereas during periods impacted by biomass burning, $\kappa_{\mathrm{a}}$ values were reduced to $0.40 \pm 0.03$ for the accumulation mode but increased instead to $0.56 \pm 0.25$ for the Aitken mode (Atwood et al., 2017).

Size-resolved CCN activities were explored over the northern South China Sea $\left(19^{\circ} 39^{\prime}\right.$ to $22^{\circ} 43^{\prime} \mathrm{N}, 113^{\circ} 44^{\prime}$ to $118^{\circ} 12^{\prime} \mathrm{E}$ ) in August 2018 (Cai et al., 2020), and no obvious dependence of $\kappa_{\mathrm{a}}$ on particle size $(50-100 \mathrm{~nm})$ was observed. The campaign-averaged $\kappa$ was determined to be $\sim 0.40$ (Cai et al., 2020), larger than these measured in the PRD region but smaller than those measured over remote marine regions. This is because the air in the northern South China Sea was affected by both continental air masses (low hygroscopicity) and marine background (high hygroscopicity). 


\section{4}

\subsection{Summary}

Similar to H-TDMA measurements, CCN activity measurements in China were mainly carried out in NCP, YRD, and PRD, and almost all the measurements took place at or close to ground level. In addition, the number of $\mathrm{CCN}$ activity measurements is much smaller than H-TDMA measurements. The limited number of field studies precludes any solid conclusions on diurnal and seasonal variations of aerosol $\mathrm{CCN}$ activities being drawn.

Maximum activation fractions were typically found to be considerably smaller than 1 (Rose et al., 2010; Gunthe et al., 2011; Che et al., 2017; Zhang et al., 2017), especially at low supersaturation, and $\mathrm{CCN}$-inactive particles were usually attributed to low hygroscopic primary particles (e.g., soot) from local sources. The average $\kappa$ values, reported by previous studies, were generally found to be in the range of 0.30 0.35; however, $\mathrm{CCN}$ activities could be significantly reduced if measurement sites were affected by fresh urban pollution or biomass burning (Rose et al., 2010; Gunthe et al., 2011; Zhang et al., 2014; Wu et al., 2017) due to enhanced contribution of soot and organics. We note that a few recent studies (Atwood et al., 2017; Zhang et al., 2017; Cai et al., 2020) also reported higher aerosol hygroscopicity, as shown in Table S5. For example, the average $\kappa$ values observed at the Xinzhou site (Zhang et al., 2017) appeared to be larger than those reported at other continental sites probably because aerosols arriving at this site were heavily aged; in addition, two studies which investigated aerosol CCN activities in the marine boundary layer reported larger $\kappa$ values (Atwood et al., 2017; Cai et al., 2020) compared to those at continental sites.

Figure 7 summarizes size dependence of $\kappa_{\mathrm{a}}$ reported by $\mathrm{CCN}$ measurements at continental sites in China, and measurement data related to specific cases (e.g., biomass burning events) are not included (Rose et al., 2010; Wu et al., 2017). As shown in Fig. 7, in general $\kappa_{\mathrm{a}}$ increased with particle size, as mass fractions increased with particle size for soluble inorganics and decreased for organics. Nevertheless, no obvious dependence of $\kappa_{\mathrm{a}}$ on particle size was also observed in Xinzhou (Zhang et al., 2017) and Nanjing (Ma et al., 2017) probably because aerosol particles at these two sites were substantially aged and thus very well internally mixed.

Several studies carried out CCN activity closure analysis. Some studies suggested that the measured $\kappa$ values could be quantitatively explained well by aerosol composition (Rose et al., 2010; Gunthe et al., 2011; Wu et al., 2017), while other studies showed that $\kappa$ values estimated using aerosol composition were either larger (Zhang et al., 2017) or smaller than measured values (Zhang et al., 2017; Cai et al., 2018). In hygroscopicity closure studies (either hygroscopic growth or CCN activity), average aerosol compositions are usually used to calculate hygroscopicity, and thus the calculated hygroscopicity represents the volume-weighted hygroscopicity of the entire aerosol population; on the other hand, H-TDMA and $\mathrm{CCN}$ measurements only provide the hygroscopicity of aerosols of specific diameters or diameter ranges. As a result, although variation trends between measured and calculated hygroscopicity may be comparable, strictly speaking a direct comparison is not physically appropriate. It would be more proper to compare measured hygroscopicity with that calculated using size-resolved chemical composition, as demonstrated by a closure study carried out by a campaign in central Germany (Wu et al., 2013).

In addition, a few studies investigated aerosol hygroscopic growth and CCN activities concurrently, and both consistencies (Wu et al., 2017; Zhang et al., 2017; Cai et al., 2018) and discrepancies (Ma et al., 2016; S. L. Zhang et al., 2016) were reported. The discrepancies could be caused by several factors (Petters and Kreidenweis, 2008; Wex et al., 2009; Petters and Kreidenweis, 2013; P. Liu et al., 2018), such as solution non-ideality of aerosol droplets, limited solubility of some components contained by aerosol particles, surface tension effects, liquid-liquid phase separation, etc.

\section{Perspectives}

In the last 10-20 years, a number of field measurements of hygroscopic properties and CCN activities of tropospheric aerosols have been carried out in China, and summaries of measured hygroscopic properties and $\mathrm{CCN}$ activities are provided in Sects. 3.5 and 4.5. As shown in Sects. 3 and 4, these studies have significantly improved our knowledge of tropospheric aerosol hygroscopicity in China and provided valuable data to better understand the roles aerosols play in heterogeneous and multiphase chemistry, as well as direct and indirect radiative forcing. However, large knowledge gaps still exist for aerosol hygroscopicity in China, as described below, and future research directions are also proposed.

\subsection{Data availability}

In Tables S1-S5, we attempt to compile measurement data reported by previous studies under a consistent framework in order to enhance their accessibility and usability. However, important data are not always available from every study published; for example, several studies presented their main results graphically. It is recommended that in the future, data in the numerical form (H-TDMA measurements, including but not limited to diameter, $\mathrm{RH}, \mathrm{GF}$, and/or $\kappa$, and $\mathrm{CCN}$ activity measurements, including but not limited to supersaturation, activation diameter, and $\kappa$ ) should be provided.

\subsection{Geographical coverages}

As shown in Sects. 3 and 4, almost all the measurements of hygroscopic properties and $\mathrm{CCN}$ activities in China were carried out in eastern regions (e.g., NCP, YRD, and PRD) heavily affected by anthropogenic emissions. Therefore, it will be very desirable in the future to carry out these measurements in other regions; measurements in areas far from human ac- 

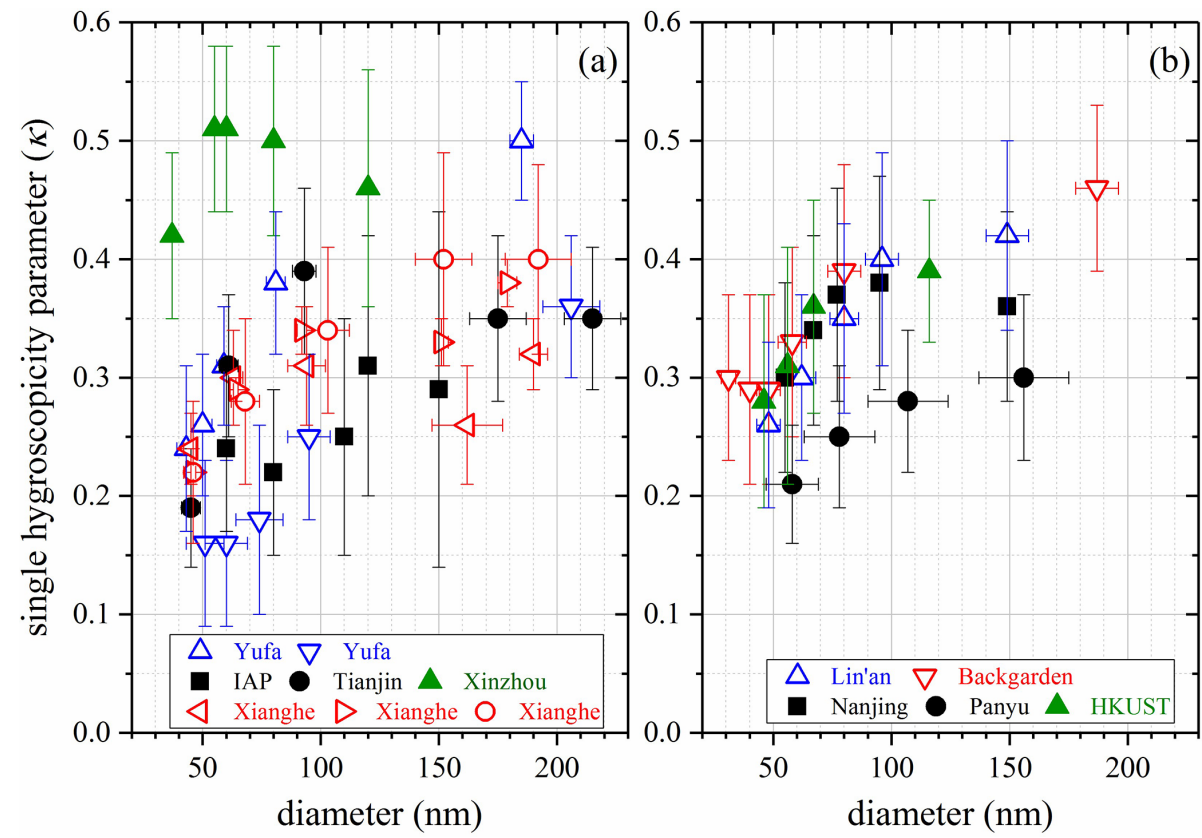

Figure 7. Measured $\kappa_{\mathrm{a}}$ as a function of particle diameter reported by previous studies (Rose et al., 2010; Deng et al., 2011; Gunthe et al., 2011; Deng et al., 2013; Meng et al., 2014; Zhang et al., 2014; Che et al., 2016; Ma et al., 2016; Che et al., 2017; Ma et al., 2017; Zhang et al., 2017; Cai et al., 2018; Tao et al., 2020) in the NCP (a) and other regions in China (b). Solid symbols represent urban and suburban sites, and open symbols represent rural sites.

tivities (e.g., Mt. Gongga in Sichuan Province, Mt. Waliguan in Qinghai Province, and Xianggelila in Yunnan Province) will be especially important as they will provide information on aerosol hygroscopicity in the cleaner troposphere.

\subsection{Vertical distribution}

Most of the previous aerosol hygroscopicity measurements in China were only carried out at or close to ground level. However, both aerosol composition and $\mathrm{RH}$, and as a result aerosol hygroscopic growth and $\mathrm{CCN}$ activation, will vary with altitude. For example, aircraft-based measurements of aerosol size distribution and composition indicated that single hygroscopicity parameters would increase significantly with altitude (Liu et al., 2020), and it was revealed from remote sensing that aerosol hygroscopicity at the upper boundary level was different from that at ground level (Tan et al., 2020). Therefore, in situ measurements of vertical profiles of aerosol composition and hygroscopicity on different platforms (e.g., towers, airships, aircrafts) will be very valuable; in addition, remote sensing may be very useful for retrieving vertical profiles of aerosol hygroscopicity, as demonstrated by a very recent study (Tan et al., 2020).

\subsection{Long-term measurements}

Both aerosol concentration and composition have undergone (and very likely will undergo) significant changes in China; however, most aerosol hygroscopicity measurements were carried out for 1-2 months during specific field campaigns. Long-term measurements of aerosol hygroscopicity will be very important to understand seasonal and annual variations of aerosol hygroscopicity and the implications for visibility, atmospheric chemistry, and climate change.

\subsection{Hygroscopicity of large particles}

Tables S1-S4 reveal that the maximum aerosol diameter examined in hygroscopic growth studies was $350 \mathrm{~nm}$, which is the upper limit of dry aerosol size for most of the HTDMA instruments (Tang et al., 2019). As particles larger than $350 \mathrm{~nm}$ can contribute substantially to aerosol surface area and volume (or mass) concentrations, hygroscopicity of these particles will be very important and should be measured in the future, and this requires technical improvements of H-TDMA. On the other hand, hygroscopicity of $>350 \mathrm{~nm}$ particles may not be very important for $\mathrm{CCN}$ activation as these particles can be easily activated at low supersaturation due to their size.

\subsection{RH dependence}

Most H-TDMA measurements were carried out at a single RH (usually 90\%), and a few studies which measured GF as a function of RH suggested that a constant $\kappa$ failed to describe hygroscopic growth at different RHs. In addition, due to lack of measurement data at different RHs, it is not clear how well widely used aerosol thermodynamic models can 
simulate ALWC at ambient RH. Therefore, measurements of aerosol hygroscopicity at different RHs are certainly warranted, and hygroscopic growth factors measured at high $\mathrm{RH}$ (at $90 \%$ RH or above) are preferably used to calculate $\kappa$ values.

\subsection{The effect of aerosol organics}

As discussed in Sect. 3, several studies (Liu et al., 2014; Wu et al., 2016; Cai et al., 2018; Hong et al., 2018; X. Li et al., 2019; Kuang et al., 2020; Jin et al., 2020) suggested that organics contributed substantially to aerosol water uptake, while some studies also indicated that the contribution of aerosol organics to ALWC was rather minor. Therefore, aerosol hygroscopicity closure analysis, with concurrent measurements of aerosol composition and hygroscopicity, is recommended for the future in order to further understand the effects of aerosol organics on ALWC and CCN activation; in addition, relevant factors which need consideration include the dependence of hygroscopicity on the composition of aerosol organics (e.g., O : C ratios) and the effects of aerosol organics on surface tension, phase separation effects, etc.

Data availability. This is a review paper, and all the data used come from the cited literature. In addition, the data we have compiled can be found in the Supplement.

Supplement. The supplement related to this article is available online at: https://doi.org/10.5194/acp-20-13877-2020-supplement.

Author contributions. MT conceived this work. CP, RH, MG, MH, $\mathrm{XW}$ and MT wrote Sects. 1, 3.5, 4.5 and 5. CP, YW, ZhWu and MT wrote Sect. 2. CP, YW, ZhWu, LC, WW, WH and MT wrote Sect. 3. CP, YW, ZhWu, ZhWa, GZ and MT wrote Sect. 4.

Competing interests. The authors declare that they have no conflict of interest.

Special issue statement. This article is part of the special issue "Multiphase chemistry of secondary aerosol formation under severe haze". It does not belong to a conference.

Acknowledgements. We would like to thank participants at the fifth International Workshop on Heterogeneous Kinetics Related to Atmospheric Aerosols for their discussions.

Financial support. This research has been supported by the National Natural Science Foundation of China (grant nos. 91744204 and 91844301), the Department of Science and Technology of
Guangdong Province (grant no. 2017GC010501), the Guangdong Foundation for Program of Science and Technology Research (grant nos. 2020B1212060053 and 2019B121205006) and the CAS Pioneer Hundred Talents program for providing a starting grant.

Review statement. This paper was edited by Jingkun Jiang and reviewed by four anonymous referees.

\section{References}

Achtert, P., Birmili, W., Nowak, A., Wehner, B., Wiedensohler, A., Takegawa, N., Kondo, Y., Miyazaki, Y., Hu, M., and Zhu, T.: Hygroscopic growth of tropospheric particle number size distributions over the North China Plain, J. Geophys. Res.-Atmos., 114, D00G07, https://doi.org/10.1029/2008JD010921, 2009.

An, Z., Huang, R.-J., Zhang, R., Tie, X., Li, G., Cao, J., Zhou, W., Shi, Z., Han, Y., Gu, Z., and Ji, Y.: Severe haze in northern China: A synergy of anthropogenic emissions and atmospheric processes, P. Natl. Acad. Sci. USA, 116, 8657-8666, 2019.

Asmi, E., Frey, A., Virkkula, A., Ehn, M., Manninen, H. E., Timonen, H., Tolonen-Kivimäki, O., Aurela, M., Hillamo, R., and Kulmala, M.: Hygroscopicity and chemical composition of Antarctic sub-micrometre aerosol particles and observations of new particle formation, Atmos. Chem. Phys., 10, 4253-4271, https://doi.org/10.5194/acp-10-4253-2010, 2010.

Atwood, S. A., Reid, J. S., Kreidenweis, S. M., Blake, D. R., Jonsson, H. H., Lagrosas, N. D., Xian, P., Reid, E. A., Sessions, W. R., and Simpas, J. B.: Size-resolved aerosol and cloud condensation nuclei $(\mathrm{CCN})$ properties in the remote marine South China Sea - Part 1: Observations and source classification, Atmos. Chem. Phys., 17, 1105-1123, https://doi.org/10.5194/acp17-1105-2017, 2017.

Bedoya-Velásquez, A. E., Navas-Guzmán, F., Granados-Muñoz, M. J., Titos, G., Román, R., Casquero-Vera, J. A., Ortiz-Amezcua, P., Benavent-Oltra, J. A., de Arruda Moreira, G., MontillaRosero, E., Hoyos, C. D., Artiñano, B., Coz, E., Olmo-Reyes, F. J., Alados-Arboledas, L., and Guerrero-Rascado, J. L.: Hygroscopic growth study in the framework of EARLINET during the SLOPE I campaign: synergy of remote sensing and in situ instrumentation, Atmos. Chem. Phys., 18, 7001-7017, https://doi.org/10.5194/acp-18-7001-2018, 2018.

Bertram, T. H. and Thornton, J. A.: Toward a general parameterization of $\mathrm{N}_{2} \mathrm{O}_{5}$ reactivity on aqueous particles: the competing effects of particle liquid water, nitrate and chloride, Atmos. Chem. Phys., 9, 8351-8363, https://doi.org/10.5194/acp-9-8351-2009, 2009.

Bian, Y. X., Zhao, C. S., Ma, N., Chen, J., and Xu, W. Y.: A study of aerosol liquid water content based on hygroscopicity measurements at high relative humidity in the North China Plain, Atmos. Chem. Phys., 14, 6417-6426, https://doi.org/10.5194/acp14-6417-2014, 2014.

Bougiatioti, A., Nenes, A., Fountoukis, C., Kalivitis, N., Pandis, S. N., and Mihalopoulos, N.: Size-resolved CCN distributions and activation kinetics of aged continental and marine aerosol, Atmos. Chem. Phys., 11, 8791-8808, https://doi.org/10.5194/acp11-8791-2011, 2011. 
Burgos, M. A., Andrews, E., Titos, G., Alados-Arboledas, L., Baltensperger, U., Day, D., Jefferson, A., Kalivitis, N., Mihalopoulos, N., Sherman, J., Sun, J., Weingartner, E., and Zieger, P.: A global view on the effect of water uptake on aerosol particle light scattering, Scientific Data, 6, 157, https://doi.org/10.1038/s41597-019-0158-7, 2019.

Burkart, J., Steiner, G., Reischl, G., and Hitzenberger, R.: Longterm study of cloud condensation nuclei $(\mathrm{CCN})$ activation of the atmospheric aerosol in Vienna, Atmos. Environ., 45, 5751-5759, 2011

Cai, M., Tan, H., Chan, C. K., Mochida, M., Hatakeyama, S., Kondo, Y., Schurman, M. I., Xu, H., Li, F., Shimada, K., Li, L., Deng, Y., Yai, H., Matsuki, A., Qin, Y., and Zhao, J.: Comparison of Aerosol Hygroscopcity, Volatility, and Chemical Composition between a Suburban Site in the Pearl River Delta Region and a Marine Site in Okinawa, Aerosol Air Qual Res., 17, 3194-3208, 2017.

Cai, M., Tan, H., Chan, C. K., Qin, Y., Xu, H., Li, F., Schurman, M. I., Liu, L., and Zhao, J.: The size-resolved cloud condensation nuclei $(\mathrm{CCN})$ activity and its prediction based on aerosol hygroscopicity and composition in the Pearl Delta River (PRD) region during wintertime 2014, Atmos. Chem. Phys., 18, 16419-16437, https://doi.org/10.5194/acp-18-16419-2018, 2018.

Cai, M., Liang, B., Sun, Q., Zhou, S., Chen, X., Yuan, B., Shao, M., Tan, H., and Zhao, J.: Effects of continental emissions on cloud condensation nuclei (CCN) activity in the northern South China Sea during summertime 2018, Atmos. Chem. Phys., 20, 9153-9167, https://doi.org/10.5194/acp-20-9153-2020, 2020.

Cerully, K. M., Raatikainen, T., Lance, S., Tkacik, D., Tiitta, P., Petäjä, T., Ehn, M., Kulmala, M., Worsnop, D. R., Laaksonen, A., Smith, J. N., and Nenes, A.: Aerosol hygroscopicity and CCN activation kinetics in a boreal forest environment during the 2007 EUCAARI campaign, Atmos. Chem. Phys., 11, 12369-12386, https://doi.org/10.5194/acp-11-12369-2011, 2011.

Che, H. C., Zhang, X. Y., Wang, Y. Q., Zhang, L., Shen, X. J., Zhang, Y. M., Ma, Q. L., Sun, J. Y., Zhang, Y. W., and Wang, T. T.: Characterization and parameterization of aerosol cloud condensation nuclei activation under different pollution conditions, Scientific Reports, 6, 24497, https://doi.org/10.1038/srep24497, 2016.

Che, H. C., Zhang, X. Y., Zhang, L., Wang, Y. Q., Zhang, Y. M., Shen, X. J., Ma, Q. L., Sun, J. Y., and Zhong, J. T.: Prediction of size-resolved number concentration of cloud condensation nuclei and long-term measurements of their activation characteristics, Scientific Reports, 7, 5819, https://doi.org/10.1038/s41598-01705998-3, 2017.

Chen, H., Yang, S., Li, Y., Yin, Y., Zhang, Z., Yu, X., Kang, N., Yan, S., and Xia, H.: Hygroscopic Properties and Closure of Aerosol Chemical Composition in Mt. Huang in Summer, Environm. Sci., 37, 2008-2016, 2016 (in Chinese).

Chen, J., Li, Z., Lv, M., Wang, Y., Wang, W., Zhang, Y., Wang, H., Yan, X., Sun, Y., and Cribb, M.: Aerosol hygroscopic growth, contributing factors, and impact on haze events in a severely polluted region in northern China, Atmos. Chem. Phys., 19, $1327-$ 1342, https://doi.org/10.5194/acp-19-1327-2019, 2019.

Chen, L. Y., Jeng, F. T., Chen, C. C., and Hsiao, T. C.: Hygroscopic behavior of atmospheric aerosol in Taipei, Atmos. Environ., 37, 2069-2075, 2003.
Cheng, Y. F., Eichler, H., Wiedensohler, A., Heintzenberg, J., Zhang, Y. H., Hu, M., Herrmann, H., Zeng, L. M., Liu, S., Gnauk, T., Brueggemann, E., and He, L. Y.: Mixing state of elemental carbon and non-light-absorbing aerosol components derived from in situ particle optical properties at Xinken in Pearl River Delta of China, J. Geophys. Res., 111, D20204, https://doi.org/10.1029/2005JD006929, 2006.

Cheung, H. H. Y., Yeung, M. C., Li, Y. J., Lee, B. P., and Chan, C. K.: Relative Humidity-Dependent HTDMA Measurements of Ambient Aerosols at the HKUST Supersite in Hong Kong, China, Aerosol Sci. Tech., 49, 643-654, 2015.

Chu, B. W., Ma, Q. X., Duan, F. K., Ma, J. Z., Jiang, J. K., He, K. B., and He, H.: Atmospheric "Haze Chemistry": Concept and Research Prospects, Prog. Chem., 32, 1-4, 2020.

Chuang, P. Y., Nenes, A., Smith, J. N., Flagan, R. C., and Seinfeld, J. H.: Design of a CCN instrument for airborne measurement, J. Atmos. Ocean. Tech., 17, 1005-1019, 2000.

Cocker, D. R., Whitlock, N. E., Flagan, R. C., and Seinfeld, J. H.: Hygroscopic properties of Pasadena, California aerosol, Aerosol Sci. Tech., 35, 637-647, 2001.

Cubison, M. J., Coe, H., and Gysel, M.: A modified hygroscopic tandem DMA and a data retrieval method based on optimal estimation, J. Aerosol Sci., 36, 846-865, 2005.

Dawson, K. W., Ferrare, R. A., Moore, R. H., Clayton, M. B., Thorsen, T. J., and Eloranta, E. W.: Ambient Aerosol Hygroscopic Growth From Combined Raman Lidar and HSRL, J. Geophys. Res.-Atmos., 125, e2019JD031708, https://doi.org/10.1029/2019JD031708, 2020.

Deng, Z. Z., Zhao, C. S., Ma, N., Liu, P. F., Ran, L., Xu, W. Y., Chen, J., Liang, Z., Liang, S., Huang, M. Y., Ma, X. C., Zhang, Q., Quan, J. N., Yan, P., Henning, S., Mildenberger, K., Sommerhage, E., Schäfer, M., Stratmann, F., and Wiedensohler, A.: Size-resolved and bulk activation properties of aerosols in the North China Plain, Atmos. Chem. Phys., 11, 3835-3846, https://doi.org/10.5194/acp-11-3835-2011, 2011.

Deng, Z. Z., Zhao, C. S., Ma, N., Ran, L., Zhou, G. Q., Lu, D. R., and Zhou, X. J.: An examination of parameterizations for the CCN number concentration based on in situ measurements of aerosol activation properties in the North China Plain, Atmos. Chem. Phys., 13, 6227-6237, https://doi.org/10.5194/acp13-6227-2013, 2013.

Ding, J., Zhang, Y. F., Zhao, P. S., Tang, M., Xiao, Z. M., Zhang, W. H., Zhang, H. T., Yu, Z. J., Du, X., Li, L. W., Yuan, J., and Feng, Y. C.: Comparison of size-resolved hygroscopic growth factors of urban aerosol by different methods in Tianjin during a haze episode, Sci. Total Environ., 678, 618-626, 2019.

Duan, J., Tao, J., Wu, Y., Cheng, T., Zhang, R., Wang, Y., Zhu, H., Xie, X., Liu, Y., Li, X., Kong, L., Li, M., and He, Q.: Comparison of aerosol and cloud condensation nuclei between wet and dry seasons in Guangzhou, southern China, Sci. Total Environ., 607, 11-22, 2017.

Duan, J., Wang, Y., Xie, X., Li, M., Tao, J., Wu, Y., Cheng, T., Zhang, R., Liu, Y., Li, X., He, Q., Gao, W., and Wang, J.: Influence of pollutants on activity of aerosol cloud condensation nuclei $(\mathrm{CCN})$ during pollution and post-rain periods in Guangzhou, southern China, Sci. Total Environ., 642, 1008-1019, 2018.

Duplissy, J., Gysel, M., Sjogren, S., Meyer, N., Good, N., Kammermann, L., Michaud, V., Weigel, R., Martins dos Santos, S., Gruening, C., Villani, P., Laj, P., Sellegri, K., Metzger, A., 
McFiggans, G. B., Wehrle, G., Richter, R., Dommen, J., Ristovski, Z., Baltensperger, U., and Weingartner, E.: Intercomparison study of six HTDMAs: results and recommendations, Atmos. Meas. Tech., 2, 363-378, https://doi.org/10.5194/amt-2363-2009, 2009.

Dusek, U., Frank, G. P., Hildebrandt, L., Curtius, J., Schneider, J., Walter, S., Chand, D., Drewnick, F., Hings, S., Jung, D., Borrmann, S., and Andreae, M. O.: Size matters more than chemistry for cloud-nucleating ability of aerosol particles, Science, 312, 1375-1378, 2006.

Eichler, H., Cheng, Y. F., Birmili, W., Nowak, A., Wiedensohler, A., Brueggemann, E., Gnauk, T., Herrmann, H., Althausen, D., Ansmann, A., Engelmann, R., Tesche, M., Wendisch, M., Zhang, Y. H., Hu, M., Liu, S., and Zeng, L. M.: Hygroscopic properties and extinction of aerosol particles at ambient relative humidity in South-Eastern China, Atmos. Environ., 42, 6321-6334, 2008.

Fajardo, O. A., Jiang, J., and Hao, J.: Continuous Measurement of Ambient Aerosol Liquid Water Content in Beijing, Aerosol Air Qual. Res., 16, 1152-1164, 2016.

Fan, X., Liu, J., Zhang, F., Chen, L., Collins, D., Xu, W., Jin, X., Ren, J., Wang, Y., Wu, H., Li, S., Sun, Y., and Li, Z.: Contrasting size-resolved hygroscopicity of fine particles derived by HTDMA and HR-ToF-AMS measurements between summer and winter in Beijing: the impacts of aerosol aging and local emissions, Atmos. Chem. Phys., 20, 915-929, https://doi.org/10.5194/acp-20-915-2020, 2020.

Fang, S., Han, Y., Chen, K., Lu, C., Yin, Y., Tan, H., and Wang, J.: Parameterization and comparative evaluation of the $\mathrm{CCN}$ number concentration on Mt. Huang, China, Atmos. Res., 181, 300-311, 2016.

Farmer, D. K., Cappa, C. D., and Kreidenweis, S. M.: Atmospheric processes and their controlling influence on cloud condensation nuclei activity, Chem. Rev., 115, 4199-4217, 2015.

Frank, G. P., Dusek, U., and Andreae, M. O.: Technical Note: Characterization of a static thermal-gradient $\mathrm{CCN}$ counter, Atmos. Chem. Phys., 7, 3071-3080, https://doi.org/10.5194/acp-7-30712007, 2007.

Fukuta, N. and Saxena, V. K.: A Horizontal Thermal Gradient Cloud Condensation Nucleus Spectrometer, J. Appl. Meteorol., 18, 1352-1362, 1979.

Gao, Y., Zhang, D., Wang, J., Gao, H., and Yao, X.: Variations in $N_{\text {cn }}$ and $N_{\text {ccn }}$ over marginal seas in China related to marine traffic emissions, new particle formation and aerosol aging, Atmos. Chem. Phys., 20, 9665-9677, https://doi.org/10.5194/acp20-9665-2020, 2020.

Good, N., Coe, H., and McFiggans, G.: Instrumentational operation and analytical methodology for the reconciliation of aerosol water uptake under sub- and supersaturated conditions, Atmos. Meas. Tech., 3, 1241-1254, https://doi.org/10.5194/amt-3-12412010, 2010.

Gunthe, S. S., Rose, D., Su, H., Garland, R. M., Achtert, P., Nowak, A., Wiedensohler, A., Kuwata, M., Takegawa, N., Kondo, Y., Hu, M., Shao, M., Zhu, T., Andreae, M. O., and Pöschl, U.: Cloud condensation nuclei $(\mathrm{CCN})$ from fresh and aged air pollution in the megacity region of Beijing, Atmos. Chem. Phys., 11, 1102311039, https://doi.org/10.5194/acp-11-11023-2011, 2011.

Guo, S., Hu, M., Zamora, M. L., Peng, J., Shang, D., Zheng, J., Du, Z., Wu, Z., Shao, M., and Zeng, L.: Elucidating severe urban haze formation in China, P. Natl. Acad. Sci. USA, 111, 17373-17378, 2014.

Gysel, M., Crosier, J., Topping, D. O., Whitehead, J. D., Bower, K. N., Cubison, M. J., Williams, P. I., Flynn, M. J., McFiggans, G. B., and Coe, H.: Closure study between chemical composition and hygroscopic growth of aerosol particles during TORCH2, Atmos. Chem. Phys., 7, 6131-6144, https://doi.org/10.5194/acp7-6131-2007, 2007.

Gysel, M., McFiggans, G. B., and Coe, H.: Inversion of tandem differential mobility analyser (TDMA) measurements, J. Aerosol Sci., 40, 134-151, 2009.

He, H., Wang, Y., Ma, Q., Ma, J., Chu, B., Ji, D., Tang, G., Liu, C., Zhang, H., and Hao, J.: Mineral dust and $\mathrm{NO}_{\mathrm{x}}$ promote the conversion of $\mathrm{SO}_{2}$ to sulfate in heavy pollution days, Scientific reports, 4, 4172, https://doi.org/10.1038/srep04172, 2014.

Hong, J., Xu, H., Tan, H., Yin, C., Hao, L., Li, F., Cai, M., Deng, X., Wang, N., Su, H., Cheng, Y., Wang, L., Petäjä, T., and Kerminen, V.-M.: Mixing state and particle hygroscopicity of organic-dominated aerosols over the Pearl River Delta region in China, Atmos. Chem. Phys., 18, 14079-14094, https://doi.org/10.5194/acp-18-14079-2018, 2018.

Huang, R.-J., Zhang, Y., Bozzetti, C., Ho, K.-F., Cao, J.-J., Han, Y., Daellenbach, K. R., Slowik, J. G., Platt, S. M., and Canonaco, F.: High secondary aerosol contribution to particulate pollution during haze events in China, Nature, 514, 218-222, 2014.

Hudson, J. G.: An Instantaneous CCN Spectrometer, J. Atmos. Ocean. Tech., 6, 1055-1065, 1989.

Hung, H.-M., Lu, W.-J., Chen, W.-N., Chang, C.-C., Chou, C. C. K., and Lin, P.-H.: Enhancement of the hygroscopicity parameter kappa of rural aerosols in northern Taiwan by anthropogenic emissions, Atmos. Environ., 84, 78-87, 2014.

Hung, H.-M., Hsu, C.-H., Lin, W.-T., and Chen, Y.-Q.: A case study of single hygroscopicity parameter and its link to the functional groups and phase transition for urban aerosols in Taipei City, Atmos. Environ., 132, 240-248, 2016.

Ji, Q., Shaw, G. E., and Cantrell, W.: A new instrument for measuring cloud condensation nuclei: Cloud condensation nucleus "remover", J. Geophys. Res.-Atmos., 103, 28013-28019, 1998.

Jiang, R., Tan, H., Tang, L., Cai, M., Yin, Y., Li, F., Liu, L., Xu, H., Chan, P. W., Deng, X., and Wu, D.: Comparison of aerosol hygroscopicity and mixing state between winter and summer seasons in Pearl River Delta region, China, Atmos. Res., 169, 160-170, 2016.

Jin, X., Wang, Y., Li, Z., Zhang, F., Xu, W., Sun, Y., Fan, X., Chen, G., Wu, H., Ren, J., Wang, Q., and Cribb, M.: Significant contribution of organics to aerosol liquid water content in winter in Beijing, China, Atmos. Chem. Phys., 20, 901-914, https://doi.org/10.5194/acp-20-901-2020, 2020.

Kim, J.-S., Kim, Y. J., and Park, K.: Measurements of hygroscopicity and volatility of atmospheric ultrafine particles in the rural Pearl River Delta area of China, Atmos. Environ., 45, 46614670, 2011.

King, S. M., Rosenoern, T., Shilling, J. E., Chen, Q., and Martin, S. T.: Increased cloud activation potential of secondary organic aerosol for atmospheric mass loadings, Atmos. Chem. Phys., 9, 2959-2971, https://doi.org/10.5194/acp-9-2959-2009, 2009.

Kreidenweis, S. M. and Asa-Awuku, A.: 5.13 - Aerosol Hygroscopicity: Particle Water Content and Its Role in Atmospheric 
Processes, in: Treatise on Geochemistry, 2nd edn., edited by: Turekian, K. K., Elsevier, Oxford, 331-361, 2014.

Kreidenweis, S. M., Koehler, K., DeMott, P. J., Prenni, A. J., Carrico, C., and Ervens, B.: Water activity and activation diameters from hygroscopicity data - Part I: Theory and application to inorganic salts, Atmos. Chem. Phys., 5, 1357-1370, https://doi.org/10.5194/acp-5-1357-2005, 2005.

Krieger, U. K., Marcolli, C., and Reid, J. P.: Exploring the complexity of aerosol particle properties and processes using single particle techniques, Chem. Soc. Rev., 41, 6631-6662, 2012.

Kuang, Y., Zhao, C., Tao, J., Bian, Y., Ma, N., and Zhao, G.: A novel method for deriving the aerosol hygroscopicity parameter based only on measurements from a humidified nephelometer system, Atmos. Chem. Phys., 17, 6651-6662, https://doi.org/10.5194/acp-17-6651-2017, 2017.

Kuang, Y., Zhao, C. S., Zhao, G., Tao, J. C., Xu, W., Ma, N., and Bian, Y. X.: A novel method for calculating ambient aerosol liquid water content based on measurements of a humidified nephelometer system, Atmos. Meas. Tech., 11, 2967-2982, https://doi.org/10.5194/amt-11-2967-2018, 2018.

Kuang, Y., He, Y., Xu, W., Zhao, P., Cheng, Y., Zhao, G., Tao, J., Ma, N., Su, H., Zhang, Y., Sun, J., Cheng, P., Yang, W., Zhang, S., Wu, C., Sun, Y., and Zhao, C.: Distinct diurnal variation in organic aerosol hygroscopicity and its relationship with oxygenated organic aerosol, Atmos. Chem. Phys., 20, 865-880, https://doi.org/10.5194/acp-20-865-2020, 2020.

Lance, S., Medina, J., Smith, J. N., and Nenes, A.: Mapping the operation of the DMT Continuous Flow CCN counter, Aerosol Sci. Tech., 40, 242-254, 2006.

Leng, C., Cheng, T., Chen, J., Zhang, R., Tao, J., Huang, G., Zha, S., Zhang, M., Fang, W., Li, X., and Li, L.: Measurements of surface cloud condensation nuclei and aerosol activity in downtown Shanghai, Atmos. Environ., 69, 354-361, 2013.

Leng, C., Zhang, Q., Zhang, D., Xu, C., Cheng, T., Zhang, R., Tao, J., Chen, J., Zha, S., Zhang, Y., Li, X., Kong, L., and Gao, W.: Variations of cloud condensation nuclei (CCN) and aerosol activity during fog-haze episode: a case study from Shanghai, Atmos. Chem. Phys., 14, 12499-12512, https://doi.org/10.5194/acp-1412499-2014, 2014.

Li, K., Zhu, Y., Gao, H., and Yao, X.: A comparative study of cloud condensation nuclei measured between non-heating and heating periods at a suburb site of Qingdao in the North China, Atmos. Environ., 112, 40-53, 2015.

Li, K., Ye, X., Pang, H., Lu, X., Chen, H., Wang, X., Yang, $\mathrm{X}$., Chen, J., and Chen, Y.: Temporal variations in the hygroscopicity and mixing state of black carbon aerosols in a polluted megacity area, Atmos. Chem. Phys., 18, 15201-15218, https://doi.org/10.5194/acp-18-15201-2018, 2018.

Li, K., Jacob, D. J., Liao, H., Shen, L., Zhang, Q., and Bates, K. H.: Anthropogenic drivers of 2013-2017 trends in summer surface ozone in China, P. Natl. Acad. Sci. USA, 116, 422-427, 2019.

Li, M., Liu, H., Geng, G., Hong, C., Liu, F., Song, Y., Tong, D., Zheng, B., Cui, H., Man, H., Zhang, Q., and He, K.: Anthropogenic emission inventories in China: a review, Natl. Sci. Rev., 4, 834-866, 2017.

Li, Q., Yin, Y., Gu, X., Yuan, L., Kong, S., Jiang, Q., Chen, K., and Li, L.: An observational study of aerosol hygroscopic growth factor and cloud condensation nuclei in Nanjing in summer, China Environmental Science, 35, 337-346, 2015 (in Chinese).
Li, W., Shao, L., Zhang, D., Ro, C.-U., Hu, M., Bi, X., Geng, H., Matsuki, A., Niu, H., and Chen, J.: A review of single aerosol particle studies in the atmosphere of East Asia: morphology, mixing state, source, and heterogeneous reactions, J. Clean. Prod., 112, 1330-1349, 2016.

Li, X., Song, S., Zhou, W., Hao, J., Worsnop, D. R., and Jiang, $\mathrm{J}$.: Interactions between aerosol organic components and liquid water content during haze episodes in Beijing, Atmos. Chem. Phys., 19, 12163-12174, https://doi.org/10.5194/acp-19-121632019, 2019.

Li, Y., Zhang, F., Li, Z., Sun, L., Wang, Z., Li, P., Sun, Y., Ren, J., Wang, Y., Cribb, M., and Yuan, C.: Influences of aerosol physiochemical properties and new particle formation on $\mathrm{CCN}$ activity from observation at a suburban site of China, Atmos. Res., 188, 80-89, 2017.

Liu, B. Y. H., Pui, D. Y. H., Whitby, K. T., Kittelson, D. B., Kousaka, Y., and McKenzie, R. L.: The aerosol mobility chromatograph: A new detector for sulfuric acid aerosols, Atmos. Environ., 12, 99 104, 1978.

Liu, H. J., Zhao, C. S., Nekat, B., Ma, N., Wiedensohler, A., van Pinxteren, D., Spindler, G., Müller, K., and Herrmann, H.: Aerosol hygroscopicity derived from size-segregated chemical composition and its parameterization in the North China Plain, Atmos. Chem. Phys., 14, 2525-2539, https://doi.org/10.5194/acp-14-2525-2014, 2014.

Liu, L., Tan, H., Fan, S., Cai, M., Xu, H., Li, F., and Chan, P.: Influence of aerosol hygroscopicity and mixing state on aerosol optical properties in the Pearl River Delta region, China, Sci. Total Environ., 627, 1560-1571, 2018.

Liu, P., Song, M., Zhao, T., Gunthe, S. S., Ham, S., He, Y., Qin, Y. M., Gong, Z., Amorim, J. C., Bertram, A. K., and Martin, S. T.: Resolving the mechanisms of hygroscopic growth and cloud condensation nuclei activity for organic particulate matter, Nat. Commun., 9, 4076, https://doi.org/10.1038/s41467-018-066222, 2018

Liu, P. F., Zhao, C. S., Göbel, T., Hallbauer, E., Nowak, A., Ran, L., Xu, W. Y., Deng, Z. Z., Ma, N., Mildenberger, K., Henning, S., Stratmann, F., and Wiedensohler, A.: Hygroscopic properties of aerosol particles at high relative humidity and their diurnal variations in the North China Plain, Atmos. Chem. Phys., 11, 3479-3494, https://doi.org/10.5194/acp-11-3479-2011, 2011.

Liu, Q., Liu, D., Gao, Q., Tian, P., Wang, F., Zhao, D., Bi, K., Wu, Y., Ding, S., Hu, K., Zhang, J., Ding, D., and Zhao, C.: Vertical characteristics of aerosol hygroscopicity and impacts on optical properties over the North China Plain during winter, Atmos. Chem. Phys., 20, 3931-3944, https://doi.org/10.5194/acp20-3931-2020, 2020.

Liu, Y., Wu, Z., Wang, Y., Xiao, Y., Gu, F., Zheng, J., Tan, T., Shang, D., Wu, Y., Zeng, L., Hu, M., Bateman, A. P., and Martin, S. T.: Submicrometer Particles Are in the Liquid State during Heavy Haze Episodes in the Urban Atmosphere of Beijing, China, Environ. Sci. Tech. Let., 4, 427-432, 2017.

Lopez-Yglesias, X. F., Yeung, M. C., Dey, S. E., Brechtel, F. J., and Chan, C. K.: Performance Evaluation of the Brechtel Mfg. Humidified Tandem Differential Mobility Analyzer (BMI HTDMA) for Studying Hygroscopic Properties of Aerosol Particles, Aerosol Sci. Tech., 48, 969-980, 2014.

Lu, G. and Guo, X.: Distribution and origin of aerosol and its transform relationship with $\mathrm{CCN}$ derived from the spring multi- 
aircraft measurements of Beijing Cloud Experiment (BCE), Chinese Science Bulletin, 57, 2460-2469, 2012.

Lu, K., Guo, S., Tan, Z., Wang, H., Shang, D., Liu, Y., Li, X., Wu, Z., Hu, M., and Zhang, Y.: Exploring atmospheric free-radical chemistry in China: the self-cleansing capacity and the formation of secondary air pollution, Natl. Sci. Rev., 6, 579-594, 2019.

Lu, X., Zhang, L., Wang, X., Gao, M., Li, K., Zhang, Y., Yue, X., and Zhang, Y.: Rapid Increases in Warm-Season Surface Ozone and Resulting Health Impact in China Since 2013, Environ. Sci. Tech. Let., 7, 240-247, 2020.

Lv, M., Liu, D., Li, Z., Mao, J., Sun, Y., Wang, Z., Wang, Y., and Xie, C.: Hygroscopic growth of atmospheric aerosol particles based on lidar, radiosonde, and in situ measurements: Case studies from the Xinzhou field campaign, J. Quant. Spectrosc. Ra., 188, 60-70, 2017.

Ma, N., Zhao, C., Tao, J., Wu, Z., Kecorius, S., Wang, Z., Größ, J., Liu, H., Bian, Y., Kuang, Y., Teich, M., Spindler, G., Müller, K., van Pinxteren, D., Herrmann, H., Hu, M., and Wiedensohler, A.: Variation of $\mathrm{CCN}$ activity during new particle formation events in the North China Plain, Atmos. Chem. Phys., 16, 8593-8607, https://doi.org/10.5194/acp-16-8593-2016, 2016.

Ma, Y., Li, S., Zheng, J., Khalizov, A., Wang, X., Wang, Z., and Zhou, Y.: Size-resolved measurements of mixing state and cloudnucleating ability of aerosols in Nanjing, China, J. Geophys. Res.-Atmos., 122, 9430-9450, 2017.

Massling, A., Stock, M., Wehner, B., Wu, Z. J., Hu, M., Brueggemann, E., Gnauk, T., Herrmann, H., and Wiedensohler, A.: Size segregated water uptake of the urban submicrometer aerosol in Beijing, Atmos. Environ., 43, 1578-1589, 2009.

Massling, A., Niedermeier, N., Hennig, T., Fors, E. O., Swietlicki, E., Ehn, M., Hämeri, K., Villani, P., Laj, P., Good, N., McFiggans, G., and Wiedensohler, A.: Results and recommendations from an intercomparison of six Hygroscopicity-TDMA systems, Atmos. Meas. Tech., 4, 485-497, https://doi.org/10.5194/amt-4485-2011, 2011.

McFiggans, G., Artaxo, P., Baltensperger, U., Coe, H., Facchini, M. C., Feingold, G., Fuzzi, S., Gysel, M., Laaksonen, A., Lohmann, U., Mentel, T. F., Murphy, D. M., O’Dowd, C. D., Snider, J. R., and Weingartner, E.: The effect of physical and chemical aerosol properties on warm cloud droplet activation, Atmos. Chem. Phys., 6, 2593-2649, https://doi.org/10.5194/acp-6-25932006, 2006.

McMurry, P. H.: A review of atmospheric aerosol measurements, Atmos. Environ., 34, 1959-1999, 2000.

McMurry, P. H. and Stolzenburg, M. R.: On the sensitivity of particle size to relative humidity for Los Angeles aerosols, Atmos. Environ., 23, 497-507, 1989.

McMurry, P. H., Takano, H., and Anderson, G. R.: Study of the ammonia (gas)-sulfuric acid (aerosol) reaction rate, Environ. Sci. Technol., 17, 347-352, 1983.

Meier, J., Wehner, B., Massling, A., Birmili, W., Nowak, A., Gnauk, T., Brüggemann, E., Herrmann, H., Min, H., and Wiedensohler, A.: Hygroscopic growth of urban aerosol particles in Beijing (China) during wintertime: a comparison of three experimental methods, Atmos. Chem. Phys., 9, 6865-6880, https://doi.org/10.5194/acp-9-6865-2009, 2009.

Meng, J. W., Yeung, M. C., Li, Y. J., Lee, B. Y. L., and Chan, C. K.: Size-resolved cloud condensation nuclei (CCN) activity and closure analysis at the HKUST Supersite in Hong Kong, Atmos.
Chem. Phys., 14, 10267-10282, https://doi.org/10.5194/acp-1410267-2014, 2014.

Moore, R. H., Nenes, A., and Medina, J.: Scanning Mobility CCN Analysis-A Method for Fast Measurements of Size-Resolved CCN Distributions and Activation Kinetics, Aerosol Sci. Tech., 44, 861-871, 2010.

Nenes, A., Chuang, P. Y., Flagan, R. C., and Seinfeld, J. H.: A theoretical analysis of cloud condensation nucleus (CCN) instruments, J. Geophys. Res.-Atmos., 106, 3449-3474, 2001.

Otto, P., Georgii, H. W., and Bingemer, H.: A new three-stage continuous flow CCN-counter, Atmos. Res., 61, 299-310, 2002.

Petters, M. D. and Kreidenweis, S. M.: A single parameter representation of hygroscopic growth and cloud condensation nucleus activity, Atmos. Chem. Phys., 7, 1961-1971, https://doi.org/10.5194/acp-7-1961-2007, 2007.

Petters, M. D. and Kreidenweis, S. M.: A single parameter representation of hygroscopic growth and cloud condensation nucleus activity - Part 2: Including solubility, Atmos. Chem. Phys., 8, 6273-6279, https://doi.org/10.5194/acp-8-6273-2008, 2008.

Petters, M. D. and Kreidenweis, S. M.: A single parameter representation of hygroscopic growth and cloud condensation nucleus activity - Part 3: Including surfactant partitioning, Atmos. Chem. Phys., 13, 1081-1091, https://doi.org/10.5194/acp13-1081-2013, 2013.

Petters, M. D., Prenni, A. J., Kreidenweis, S. M., and DeMott, P. J.: On measuring the critical diameter of cloud condensation nuclei using mobility selected aerosol, Aerosol Sci. Tech., 41, 907-913, 2007.

Petters, M. D., Carrico, C. M., Kreidenweis, S. M., Prenni, A. J., DeMott, P. J., Collett Jr., J. L., and Moosmueller, H.: Cloud condensation nucleation activity of biomass burning aerosol, J. Geophys. Res., 114, D22205, https://doi.org/10.1029/2009JD012353, 2009.

Qian, X., Zhang, Q., Xu, X., Fang, B., Zhao, W., Bao, J., and Zhang, W.: Development of a Volatility Hygroscopic Tandem Differential Mobility Analyzer (VH-TDMA) for the measurement of aerosol thermal and hygroscopic properties, China Environmental Science, 37, 1269-1275, 2017 (in Chinese).

Rader, D. J. and McMurry, P. H.: Application of the tandem differential mobility analyzer to studies of droplet growth or evaporation, J. Aerosol Sci., 17, 771-787, 1986.

Ren, J., Zhang, F., Wang, Y., Collins, D., Fan, X., Jin, X., Xu, W., Sun, Y., Cribb, M., and Li, Z.: Using different assumptions of aerosol mixing state and chemical composition to predict $\mathrm{CCN}$ concentrations based on field measurements in urban Beijing, Atmos. Chem. Phys., 18, 6907-6921, https://doi.org/10.5194/acp18-6907-2018, 2018.

Riemer, N., Ault, A. P., West, M., Craig, R. L., and Curtis, J. H.: Aerosol Mixing State: Measurements, Modeling, and Impacts, Rev. Geophys., 57, 187-249, 2019.

Roberts, G. C. and Nenes, A.: A continuous-flow streamwise thermal-gradient $\mathrm{CCN}$ chamber for atmospheric measurements, Aerosol Sci. Tech., 39, 206-221, 2005.

Rose, D., Gunthe, S. S., Mikhailov, E., Frank, G. P., Dusek, U., Andreae, M. O., and Pöschl, U.: Calibration and measurement uncertainties of a continuous-flow cloud condensation nuclei counter (DMT-CCNC): CCN activation of ammonium sulfate and sodium chloride aerosol particles in theory and experiment, 
Atmos. Chem. Phys., 8, 1153-1179, https://doi.org/10.5194/acp8-1153-2008, 2008.

Rose, D., Nowak, A., Achtert, P., Wiedensohler, A., Hu, M., Shao, M., Zhang, Y., Andreae, M. O., and Pöschl, U.: Cloud condensation nuclei in polluted air and biomass burning smoke near the mega-city Guangzhou, China - Part 1: Size-resolved measurements and implications for the modeling of aerosol particle hygroscopicity and CCN activity, Atmos. Chem. Phys., 10, 33653383, https://doi.org/10.5194/acp-10-3365-2010, 2010.

Rose, D., Gunthe, S. S., Su, H., Garland, R. M., Yang, H., Berghof, M., Cheng, Y. F., Wehner, B., Achtert, P., Nowak, A., Wiedensohler, A., Takegawa, N., Kondo, Y., Hu, M., Zhang, Y., Andreae, M. O., and Pöschl, U.: Cloud condensation nuclei in polluted air and biomass burning smoke near the megacity Guangzhou, China - Part 2: Size-resolved aerosol chemical composition, diurnal cycles, and externally mixed weakly CCN-active soot particles, Atmos. Chem. Phys., 11, 2817-2836, https://doi.org/10.5194/acp-11-2817-2011, 2011.

Sinnarwalla, A. M. and Alofs, D. J.: A cloud nucleus counter with long available growth time, J. Appl. Meteorol., 12, 831-835, 1973.

Sjogren, S., Gysel, M., Weingartner, E., Alfarra, M. R., Duplissy, J., Cozic, J., Crosier, J., Coe, H., and Baltensperger, U.: Hygroscopicity of the submicrometer aerosol at the high-alpine site Jungfraujoch, $3580 \mathrm{~m}$ a.s.l., Switzerland, Atmos. Chem. Phys., 8, 5715-5729, https://doi.org/10.5194/acp-8-5715-2008, 2008.

Snider, J. R., Petters, M. D., Wechsler, P., and Liu, P. S. K.: Supersaturation in the Wyoming CCN instrument, J. Atmos. Ocean. Tech., 23, 1323-1339, 2006.

Stolzenburg, M. R. and McMurry, P. H.: TDMAfit User's Manual, Particle Technology Laboratory, Department of Mechanical Engineering, University of Minnesota, Minneapolis, MN 55455, 1988.

Stratmann, F., Kauffeldt, T., Hummes, D., and Fissan, H.: Differential electrical mobility analysis: A theoretical study, Aerosol Sci. Tech., 26, 368-383, 1997.

Sullivan, R. C., Moore, M. J. K., Petters, M. D., Kreidenweis, S. M., Roberts, G. C., and Prather, K. A.: Effect of chemical mixing state on the hygroscopicity and cloud nucleation properties of calcium mineral dust particles, Atmos. Chem. Phys., 9, 33033316, https://doi.org/10.5194/acp-9-3303-2009, 2009.

Svenningsson, B., Rissler, J., Swietlicki, E., Mircea, M., Bilde, M., Facchini, M. C., Decesari, S., Fuzzi, S., Zhou, J., Mønster, J., and Rosenørn, T.: Hygroscopic growth and critical supersaturations for mixed aerosol particles of inorganic and organic compounds of atmospheric relevance, Atmos. Chem. Phys., 6, 1937-1952, https://doi.org/10.5194/acp-6-1937-2006, 2006.

Swietlicki, E., Hansson, H. C., Hameri, K., Svenningsson, B., Massling, A., McFiggans, G., McMurry, P. H., Petaja, T., Tunved, P., Gysel, M., Topping, D., Weingartner, E., Baltensperger, U., Rissler, J., Wiedensohler, A., and Kulmala, M.: Hygroscopic properties of submicrometer atmospheric aerosol particles measured with H-TDMA instruments in various environments - a review, Tellus B, 60, 432-469, 2008.

Tan, H., Yin, Y., Gu, X., Li, F., Chan, P. W., Xu, H., Deng, X., and Wan, Q.: An observational study of the hygroscopic properties of aerosols over the Pearl River Delta region, Atmos. Environ., 77, 817-826, 2013.
Tan, H., Cai, M., Fan, Q., Liu, L., Li, F., Chan, P. W., Deng, X., and Wu, D.: An analysis of aerosol liquid water content and related impact factors in Pearl River Delta, Sci. Total Environ., 579, 1822-1830, 2017.

Tan, W., Yu, Y., Li, C., Li, J., Kang, L., Dong, H., Zeng, L., and Zhu, T.: Profiling Aerosol Liquid Water Content Using a Polarization Lidar, Environ. Sci. Technol., 54, 3129-3137, 2020.

Tan, Z., Rohrer, F., Lu, K., Ma, X., Bohn, B., Broch, S., Dong, H., Fuchs, H., Gkatzelis, G. I., Hofzumahaus, A., Holland, F., Li, X., Liu, Y., Liu, Y., Novelli, A., Shao, M., Wang, H., Wu, Y., Zeng, L., Hu, M., Kiendler-Scharr, A., Wahner, A., and Zhang, Y.: Wintertime photochemistry in Beijing: observations of ROx radical concentrations in the North China Plain during the BEST-ONE campaign, Atmos. Chem. Phys., 18, 12391-12411, https://doi.org/10.5194/acp-18-12391-2018, 2018.

Tang, M., Cziczo, D. J., and Grassian, V. H.: Interactions of Water with Mineral Dust Aerosol: Water Adsorption, Hygroscopicity, Cloud Condensation, and Ice Nucleation, Chem. Rev., 116, 4205-4259, 2016.

Tang, M., Huang, X., Lu, K., Ge, M., Li, Y., Cheng, P., Zhu, T., Ding, A., Zhang, Y., Gligorovski, S., Song, W., Ding, X., Bi, X., and Wang, X.: Heterogeneous reactions of mineral dust aerosol: implications for tropospheric oxidation capacity, Atmos. Chem. Phys., 17, 11727-11777, https://doi.org/10.5194/acp-17-117272017, 2017.

Tang, M., Chan, C. K., Li, Y. J., Su, H., Ma, Q., Wu, Z., Zhang, G., Wang, Z., Ge, M., Hu, M., He, H., and Wang, X.: A review of experimental techniques for aerosol hygroscopicity studies, Atmos. Chem. Phys., 19, 12631-12686, https://doi.org/10.5194/acp-1912631-2019, 2019.

Tao, J., Kuang, Y., Ma, N., Zheng, Y., Wiedensohler, A., and Zhao, C.: An improved parameterization scheme for sizeresolved particle activation ratio and its application on comparison study of particle hygroscopicity measurements between HTDMA and DMA-CCNC, Atmos. Environ., 226, 117403 , https://doi.org/10.1016/j.atmosenv.2020.117403, 2020.

Titos, G., Cazorla, A., Zieger, P., Andrews, E., Lyamani, H., Granados-Muñoz, M., Olmo, F., and Alados-Arboledas, L.: Effect of hygroscopic growth on the aerosol light-scattering coefficient: A review of measurements, techniques and error sources, Atmos. Environ., 141, 494-507, 2016.

Twomey, S.: Measurements of natural cloud nuclei, Journal de Recherches Atmospheriques, 1, 101-105, 1963.

VanReken, T. M., Nenes, A., Flagan, R. C., and Seinfeld, J. H.: Concept for a new cloud condensation nucleus $(\mathrm{CCN})$ spectrometer, Aerosol Sci. Tech., 38, 639-654, 2004.

Voutilainen, A., Stratmann, F., and Kaipio, J. P.: A nonhomogeneous regularization method for the estimation of narrow aerosol size distributions, J. Aerosol Sci., 31, 1433-1445, 2000.

Wang, H., Lu, K., Chen, X., Zhu, Q., Chen, Q., Guo, S., Jiang, M., Li, X., Shang, D., and Tan, Z.: High $\mathrm{N}_{2} \mathrm{O}_{5}$ Concentrations Observed in Urban Beijing: Implications of a Large Nitrate Formation Pathway, Environ. Sci. Tech. Lett., 4, 416-420, 2017.

Wang, J., Shen, Y., Li, K., Gao, Y., Gao, H., and Yao, X.: Nucleation-mode particle pool and large increases in $N_{\mathrm{cn}}$ and $N_{\text {ccn }}$ observed over the northwestern Pacific Ocean in the spring of 2014, Atmos. Chem. Phys., 19, 8845-8861, https://doi.org/10.5194/acp-19-8845-2019, 2019. 
Wang, Q., Yang, S., Li, Y., Yin, Y., Zhang, Z., Chen, K., and Zhao, L.: A study of multi-size aerosol hygroscopic parameterization in the summer over Huangshan Mountain, Acta Meteorol. Sin., 74, 989-1001, 2016 (in Chinese).

Wang, T., Xue, L., Brimblecombe, P., Lam, Y. F., Li, L., and Zhang, L.: Ozone pollution in China: A review of concentrations, meteorological influences, chemical precursors, and effects, Sci. Total Environ., 575, 1582-1596, 2017.

Wang, X., Ye, X., Chen, H., Chen, J., Yang, X., and Gross, D. S.: Online hygroscopicity and chemical measurement of urban aerosol in Shanghai, China, Atmos. Environ., 95, 318-326, 2014.

Wang, X., Shen, X. J., Sun, J. Y., Zhang, X. Y., Wang, Y. Q., Zhang, Y. M., Wang, P., Xia, C., Qi, X. F., and Zhong, J. T.: Sizeresolved hygroscopic behavior of atmospheric aerosols during heavy aerosol pollution episodes in Beijing in December 2016, Atmos. Environ., 194, 188-197, 2018.

Wang, X., Ye, X., Chen, J., Wang, X., Yang, X., Fu, T.-M., Zhu, L., and Liu, C.: Direct links between hygroscopicity and mixing state of ambient aerosols: estimating particle hygroscopicity from their single-particle mass spectra, Atmos. Chem. Phys., 20, 6273-6290, https://doi.org/10.5194/acp-20-6273-2020, 2020.

Wang, Y., Wu, Z., and Hu, M.: Hygroscopicity of atmospheric submicrometer particles in various environments in China, China Environmental Science, 37, 1601-1609, 2017a (in Chinese).

Wang, Y., Zhang, F., Li, Z., Tan, H., Xu, H., Ren, J., Zhao, J., Du, W., and Sun, Y.: Enhanced hydrophobicity and volatility of submicron aerosols under severe emission control conditions in Beijing, Atmos. Chem. Phys., 17, 5239-5251, https://doi.org/10.5194/acp-17-5239-2017, 2017b.

Wang, Y., Li, Z., Zhang, Y., Du, W., Zhang, F., Tan, H., Xu, H., Fan, T., Jin, X., Fan, X., Dong, Z., Wang, Q., and Sun, Y.: Characterization of aerosol hygroscopicity, mixing state, and CCN activity at a suburban site in the central North China Plain, Atmos. Chem. Phys., 18, 11739-11752, https://doi.org/10.5194/acp-18-117392018, 2018a.

Wang, Y., Wu, Z., Ma, N., Wu, Y., Zeng, L., Zhao, C., and Wiedensohler, A.: Statistical analysis and parameterization of the hygroscopic growth of the sub-micrometer urban background aerosol in Beijing, Atmos. Environ., 175, 184-191, 2018b.

Wang, Y., Li, Z., Zhang, R., Jin, X., Xu, W., Fan, X., Wu, H., Zhang, F., Sun, Y., Wang, Q., Cribb, M., and Hu, D.: Distinct Ultrafineand Accumulation-Mode Particle Properties in Clean and Polluted Urban Environments, Geophys. Res. Lett., 46, 1091810925, 2019.

Wang, Y., Chen, Y., Wu, Z., Shang, D., Bian, Y., Du, Z., Schmitt, S. H., Su, R., Gkatzelis, G. I., Schlag, P., Hohaus, T., Voliotis, A., Lu, K., Zeng, L., Zhao, C., Alfarra, M. R., McFiggans, G., Wiedensohler, A., Kiendler-Scharr, A., Zhang, Y., and $\mathrm{Hu}$, M.: Mutual promotion between aerosol particle liquid water and particulate nitrate enhancement leads to severe nitratedominated particulate matter pollution and low visibility, Atmos. Chem. Phys., 20, 2161-2175, https://doi.org/10.5194/acp20-2161-2020, 2020.

Wex, H., Petters, M. D., Carrico, C. M., Hallbauer, E., Massling, A., McMeeking, G. R., Poulain, L., Wu, Z., Kreidenweis, S. M., and Stratmann, F.: Towards closing the gap between hygroscopic growth and activation for secondary organic aerosol: Part $1-$ Evidence from measurements, Atmos. Chem. Phys., 9, 3987-3997, https://doi.org/10.5194/acp-9-3987-2009, 2009.
Wiedensohler, A., Cheng, Y. F., Nowak, A., Wehner, B., Achtert, P., Berghof, M., Birmili, W., Wu, Z. J., Hu, M., Zhu, T., Takegawa, N., Kita, K., Kondo, Y., Lou, S. R., Hofzumahaus, A., Holland, F., Wahner, A., Gunthe, S. S., Rose, D., Su, H., and Poeschl, U.: Rapid aerosol particle growth and increase of cloud condensation nucleus activity by secondary aerosol formation and condensation: A case study for regional air pollution in northeastern China, J. Geophys. Res.-Atmos., 114, D00G08, https://doi.org/10.1029/2008JD010884, 2009.

Wu, Y., Yin, Y., Gu, X., and Tan, H.: An observational study of the hygroscopic properties of aerosols in north suburb of Nanjing, China Environmental Science, 34, 1938-1949, 2014 (in Chinese).

Wu, Y., Qiu, Y., Guo, J., Wang, K., Wang, J., and Zhou, X.: An Observational Study on the Hygroscopic Properties of Aerosol Particles at Different Altitudes: A Case Study in the Mt. Huangshan, Resources and Environment in the Yangtze Basin, 27, 13611370, 2018 (in Chinese).

Wu, Z., Zheng, J., Wang, Y., Shang, D., Du, Z., Zhang, Y., and $\mathrm{Hu}, \mathrm{M}$.: Chemical and physical properties of biomass burning aerosols and their CCN activity: A case study in Beijing, China, Sci. Total Environ., 579, 1260-1268, 2017.

Wu, Z., Chen, J., Wang, Y., Zhu, Y., Liu, Y., Yao, B., Zhang, Y., and $\mathrm{Hu}, \mathrm{M}$.: Interactions between water vapor and atmospheric aerosols have key roles in air quality and climate change, Natl. Sci. Rev., 5, 452-454, 2018.

Wu, Z. J., Nowak, A., Poulain, L., Herrmann, H., and Wiedensohler, A.: Hygroscopic behavior of atmospherically relevant water-soluble carboxylic salts and their influence on the water uptake of ammonium sulfate, Atmos. Chem. Phys., 11, 1261712626, https://doi.org/10.5194/acp-11-12617-2011, 2011.

Wu, Z. J., Poulain, L., Henning, S., Dieckmann, K., Birmili, W., Merkel, M., van Pinxteren, D., Spindler, G., Müller, K., Stratmann, F., Herrmann, H., and Wiedensohler, A.: Relating particle hygroscopicity and $\mathrm{CCN}$ activity to chemical composition during the HCCT-2010 field campaign, Atmos. Chem. Phys., 13, 79837996, https://doi.org/10.5194/acp-13-7983-2013, 2013.

Wu, Z. J., Zheng, J., Shang, D. J., Du, Z. F., Wu, Y. S., Zeng, L. M., Wiedensohler, A., and Hu, M.: Particle hygroscopicity and its link to chemical composition in the urban atmosphere of Beijing, China, during summertime, Atmos. Chem. Phys., 16, 11231138, https://doi.org/10.5194/acp-16-1123-2016, 2016.

Xie, Y., Ye, X., Ma, Z., Tao, Y., Wang, R., Zhang, C., Yang, X., Chen, J., and Chen, H.: Insight into winter haze formation mechanisms based on aerosol hygroscopicity and effective density measurements, Atmos. Chem. Phys., 17, 7277-7290, https://doi.org/10.5194/acp-17-7277-2017, 2017.

$\mathrm{Xu}, \mathrm{B} .:$ Hygroscopic properties of aerosol particles in Nanjing and Mount Huangshan, Master of Science, School of Atmospheric Physics, Nanjing University of Information Science and Technology, Nanjing, China, 31-45, 2015 (in Chinese).

Xu, B., Zhang, Z.-F., Li, Y.-W., Qin, X., Miao, Q., and Shen, Y.: Hygroscopic Properties of Aerosol Particles in North Suburb of Nanjing in Spring, Huan Jing ke Xue= Huanjing Kexue, 36, 1911-1918, 2015 (in Chinese).

Yan, Y., Fu, P., Jing, B., Peng, C., Boreddy, S. K. R., Yang, F., Wei, L., Sun, Y., Wang, Z., and Ge, M.: Hygroscopic behavior of water-soluble matter in marine aerosols over the East China Sea, Sci. Total Environ., 578, 307-316, 2017. 
Yang, F., Xue, H., Deng, Z., Zhao, C., and Zhang, Q.: A closure study of cloud condensation nuclei in the North China Plain using droplet kinetic condensational growth model, Atmos. Chem. Phys., 12, 5399-5411, https://doi.org/10.5194/acp12-5399-2012, 2012.

Yang, S., Tian, Z., Zhang, T., Yu, X., Li, Y., An, J., Zhao, X., Li, Y., Wang, Z., and Wu, S.: Urban Aerosol Hygroscopicity During Haze Weather, Environm. Sci., 40, 2546-2555, 2019 (in Chinese).

Ye, X., Ma, Z., Hu, D., Yang, X., and Chen, J.: Size-resolved hygroscopicity of submicrometer urban aerosols in Shanghai during wintertime, Atmos. Res., 99, 353-364, 2011.

Ye, X., Tang, C., Yin, Z., Chen, J., Ma, Z., Kong, L., Yang, X., Gao, W., and Geng, F.: Hygroscopic growth of urban aerosol particles during the 2009 Mirage-Shanghai Campaign, Atmos. Environ., 64, 263-269, 2013.

Yeung, M. C., Lee, B. P., Li, Y. J., and Chan, C. K.: Simultaneous HTDMA and HR-ToF-AMS measurements at the HKUST Supersite in Hong Kong in 2011, J. Geophys. Res.-Atmos., 119, 9864-9883, 2014.

Zhang, F., Li, Y., Li, Z., Sun, L., Li, R., Zhao, C., Wang, P., Sun, Y., Liu, X., Li, J., Li, P., Ren, G., and Fan, T.: Aerosol hygroscopicity and cloud condensation nuclei activity during the $\mathrm{AC}^{3}$ Exp campaign: implications for cloud condensation nuclei parameterization, Atmos. Chem. Phys., 14, 13423-13437, https://doi.org/10.5194/acp-14-13423-2014, 2014.

Zhang, F., Li, Z., Li, Y., Sun, Y., Wang, Z., Li, P., Sun, L., Wang, P., Cribb, M., Zhao, C., Fan, T., Yang, X., and Wang, Q.: Impacts of organic aerosols and its oxidation level on CCN activity from measurement at a suburban site in China, Atmos. Chem. Phys., 16, 5413-5425, https://doi.org/10.5194/acp-165413-2016, 2016.

Zhang, F., Wang, Y., Peng, J., Ren, J., Collins, D., Zhang, R., Sun, Y., Yang, X., and Li, Z.: Uncertainty in Predicting CCN Activity of Aged and Primary Aerosols, J. Geophys. Res.-Atmos., 122, 11723-11736, 2017.

Zhang, F., Ren, J., Fan, T., Chen, L., Xu, W., Sun, Y., Zhang, R., Liu, J., Jiang, S., Jin, X., Wu, H., Li, S., Cribb, M. C., and Li, Z.: Significantly Enhanced Aerosol CCN Activity and Number Concentrations by Nucleation-Initiated Haze Events: A Case Study in Urban Beijing, J. Geophys. Res.-Atmos., 124, 14102-14113, 2019.

Zhang, J., Wang, L., Chen, J., Feng, S., Shen, J., and Jiao, L.: Hygroscopicity of ambient submicron particles in urban Hangzhou, China, Front. Environ. Sci. En., 5, 342-347, 2011.
Zhang, Q., Meng, J., Quan, J., Gao, Y., Zhao, D., Chen, P., and $\mathrm{He}, \mathrm{H}$.: Impact of aerosol composition on cloud condensation nuclei activity, Atmos. Chem. Phys., 12, 3783-3790, https://doi.org/10.5194/acp-12-3783-2012, 2012.

Zhang, Q., Zheng, Y., Tong, D., Shao, M., Wang, S., Zhang, Y., Xu, X., Wang, J., He, H., Liu, W., Ding, Y., Lei, Y., Li, J., Wang, Z., Zhang, X., Wang, Y., Cheng, J., Liu, Y., Shi, Q., Yan, L., Geng, G., Hong, C., Li, M., Liu, F., Zheng, B., Cao, J., Ding, A., Gao, J., Fu, Q., Huo, J., Liu, B., Liu, Z., Yang, F., He, K., and Hao, J.: Drivers of improved PM2.5 air quality in China from 2013 to 2017, P. Natl. Acad. Sci. USA, 116, 24463-24469, 2019.

Zhang, R., Wang, G., Guo, S., Zarnora, M. L., Ying, Q., Lin, Y., Wang, W., Hu, M., and Wang, Y.: Formation of Urban Fine Particulate Matter, Chem. Rev., 115, 3803-3855, 2015.

Zhang, R., Tang, L., Xu, H., Du, S., Qin, W., Jiang, L., Tan, H., Liu, J., and Yang, Y.: Hygroscopic properties of urban aerosol in Nanjing during wintertime, Acta Scientiae Circumstantiae, 38, 32-40, 2018 (in Chinese).

Zhang, S. L., Ma, N., Kecorius, S., Wang, P. C., Hu, M., Wang, Z. B., Groess, J., Wu, Z. J., and Wiedensohler, A.: Mixing state of atmospheric particles over the North China Plain, Atmos. Environ., 125, 152-164, 2016.

Zhang, X., Xu, X., Ding, Y., Liu, Y., Zhang, H., Wang, Y., and Zhong, J.: The impact of meteorological changes from 2013 to 2017 on $\mathrm{PM}_{2.5}$ mass reduction in key regions in China, Science China-Earth Sciences, 62, 1885-1902, 2019.

Zhao, C., Yu, Y., Kuang, Y., Tao, J., and Zhao, G.: Recent Progress of Aerosol Light-scattering Enhancement Factor Studies in China, Adv. Atmos. Sci., 36, 1015-1026, 2019.

Zhu, T., Shang, J., and Zhao, D.: The roles of heterogeneous chemical processes in the formation of an air pollution complex and gray haze, Science China Chemistry, 54, 145-153, 2011.

Zhu, Y., Li, K., Shen, Y., Gao, Y., Liu, X., Yu, Y., Gao, H., and Yao, X.: New particle formation in the marine atmosphere during seven cruise campaigns, Atmos. Chem. Phys., 19, 89-113, https://doi.org/10.5194/acp-19-89-2019, 2019.

Zieger, P., Vaisanen, O., Corbin, J. C., Partridge, D. G., Bastelberger, S., Mousavi-Fard, M., Rosati, B., Gysel, M., Krieger, U. K., Leck, C., Nenes, A., Riipinen, I., Virtanen, A., and Salter, M. E.: Revising the hygroscopicity of inorganic sea salt particles, Nature Communications, 8, 15883, https://doi.org/10.1038/ncomms15883, 2017. 